\title{
A Systematic Framework for Drug Repositioning from Integrated Omics and Drug Phenotype Profiles Using Pathway-Drug Network
}

\author{
Erkhembayar Jadamba ${ }^{1}$ and Miyoung Shin ${ }^{2}$ \\ ${ }^{1}$ Bio-Intelligence \& Data Mining Laboratory, Graduate School of Electrical Engineering and Computer Science, \\ Kyungpook National University, 1370 Sangyeok-dong, Buk-gu, Daegu 702-701, Republic of Korea \\ ${ }^{2}$ School of Electronics Engineering, Kyungpook National University, 1370 Sangyeok-dong, Buk-gu, Daegu 702-701, Republic of Korea \\ Correspondence should be addressed to Miyoung Shin; shinmy@knu.ac.kr
}

Received 17 June 2016; Revised 12 October 2016; Accepted 20 October 2016

Academic Editor: Md. Altaf-Ul-Amin

Copyright (C) 2016 E. Jadamba and M. Shin. This is an open access article distributed under the Creative Commons Attribution License, which permits unrestricted use, distribution, and reproduction in any medium, provided the original work is properly cited.

\begin{abstract}
Drug repositioning offers new clinical indications for old drugs. Recently, many computational approaches have been developed to repurpose marketed drugs in human diseases by mining various of biological data including disease expression profiles, pathways, drug phenotype expression profiles, and chemical structure data. However, despite encouraging results, a comprehensive and efficient computational drug repositioning approach is needed that includes the high-level integration of available resources. In this study, we propose a systematic framework employing experimental genomic knowledge and pharmaceutical knowledge to reposition drugs for a specific disease. Specifically, we first obtain experimental genomic knowledge from disease gene expression profiles and pharmaceutical knowledge from drug phenotype expression profiles and construct a pathway-drug network representing a priori known associations between drugs and pathways. To discover promising candidates for drug repositioning, we initialize node labels for the pathway-drug network using identified disease pathways and known drugs associated with the phenotype of interest and perform network propagation in a semisupervised manner. To evaluate our method, we conducted some experiments to reposition 1309 drugs based on four different breast cancer datasets and verified the results of promising candidate drugs for breast cancer by a two-step validation procedure. Consequently, our experimental results showed that the proposed framework is quite useful approach to discover promising candidates for breast cancer treatment.
\end{abstract}

\section{Introduction}

Developing and discovering a new drug is a very costly and time consuming process, which can take 10-17 years with a cost of 1.3 billion dollars. Despite large investments in research and development each year, there are still only a small number of new drugs approved successfully by the Food and Drug Administration (FDA) each year. Increasing failure rates, high costs, and the lengthy testing process for drug development have led to a process called drug repositioning [1], which refers to identifying and developing new uses for existing drugs to reduce the risk and cost.

Traditional drug repositioning methods primarily use information on chemical structure, side effects, and drug phenotypes and explore similar drugs based on the assumption that structurally similar drugs tend to share common indications [2-4]. In other words, the key idea behind these approaches is that molecularly similar drug structures often affect proteins and biological systems in similar ways [4]. For example, Swamidass [5] used chemical structure data to identify unexpected connections between a known drug and a disease and explored the hypothesis that if a drug has the same target as a known drug, then this new drug would also have activity against the disease. As another approach, Keiser et al. used 3665 US FDA-approved and investigational drugs that together had hundreds of targets, defining each target by its ligands. The chemical similarities between the drugs and ligand sets predicted thousands of unanticipated associations, 
which have been used to develop new indications for many drugs.

Alternatively, some approaches use a drug phenotype, which is the expression profile of patients undergoing treatment with a drug. For example, the Connectivity Map (CMap) [6,7] project is exploring the effects of a large number of FDA-approved chemicals (1309 drugs) on gene expression, and these effects are measured in four different cell lines, allowing researchers to analyze the different expression patterns of drug's target genes. Many computational approaches have been introduced to reposition drugs using CMap by analyzing drug-associated expression signatures to match a repositioned drug's effect with a shared perturbed gene expression profile for another disease, under the assumption that drugs that share similar CMap expression signatures have similar therapeutic applications. Using the CMap data, Iorio et al. [8] developed a drug repositioning method by constructing a drug-drug similarity network using gene set enrichment analysis (GSEA) [9] that could compute the similarity between pairs of drugs. Several different studies $[3,10-13]$ showed that using CMap expression profiles with a combination of various data sources such as drug target databases, drug chemical structures, and drug side effects was an improvement over the current drug target identification methods.

Moreover, the rapid developments in genomics and highthroughput technologies have produced a large volume of disease gene expression profiles, protein-protein interactions, and pathways. The high-level integration of these resources using network-based approaches is reported to have great potential for discovering novel drug indications for existing drugs [14]. For example, Chen et al. [15] introduced two different inference methods for predicting drug-disease associations based on basic network topology using a bipartite graph constructed from DrugBank [16] and Online Mendelian Inheritance in Man (OMIM) [17]. Emig et al. [18] integrated gene expression profiles, drug targets, disease information, and interactions for drug repositioning. $\mathrm{Hu}$ and Agarwal [19] created a disease-drug network using disease microarray datasets and predicted new indications for existing drugs using their disease-drug network.

Although many of the above methods have shown encouraging results for finding new indications for old drugs, there are still some limitations. For example, Yildirim et al. [20] concluded that most drugs with distinct chemical structures target the same proteins, and Keiser et al. [21] reported that structurally similar drugs may also target proteins with dissimilar functions, stating that using chemical structure alone is insufficient for successful drug repositioning [22]. In addition, care should be taken when using only the drug phenotype (drug treated) expression profile (such as CMAP) for drug repositioning because some portion of the genes or pathways that show statistically significant expression differences in cell lines treated with the drug may be expressed only because of the drug's side effects or toxicity. Furthermore, the genes expressed in the drug treated profiles for specific disease cell line or tissue only represent a small subset of the biological pathways, whereas the cooperation of genes plays an important role in complex diseases such as cancer. Pathway-based drug repositioning may be a better alternative for drug repositioning for specific diseases such as cancer.

To overcome the above limitations, the current drug repositioning methods require a comprehensive and efficient computational drug repositioning approach that incorporates powerful machine learning approaches using the highlevel integration of available data such as disease gene expression profiles (disease profile), drug treated expression profiles (drug phenotype profile), and drug databases (STITCH [23], DrugBank [16], therapeutic target database (TTD) [24]) to discover new drugs for a human diseases. In this study, we aim to develop a systematic computation framework that repositions drugs by employing disease profile and drug phenotype profiles on the drug network along with integrated omics data.

\section{Materials and Methods}

In the framework as shown in Figure 1, we firstly identify disease-specific pathways by using an integrative analysis of multiple disease gene expression profiles and construct a pathway-drug network structure using pathway-drug associations derived from the CMap drug phenotype profile. Then to discover promising candidates, for drug repositioning, we initialize node labels for the pathway-drug network using identified disease pathways and known drugs associated with breast cancer and perform network propagation in a semisupervised manner.

In the following, the detailed explanations of our proposed framework for repositioning and evaluation method are described.

\subsection{Finding Disease-Specific Pathways from Multiple Disease} Expression Profiles. To identify disease pathways related to a specific disease, conventional approaches have usually focused on identifying enriched pathways between cases and controls using data from a single experiment. Specifically, when using real experimental data such as microarray gene expression data, it is possible for different studies to report different results for disease-specific pathways. That is, the results are often not reproducible or not robust even to the mildest data perturbation, so the integrated analysis of multiple existing studies can increase the reliability and generalizability of results [25]. To address these issues, our approach identifies a disease-specific pathway based on disease pathway enrichment using multiple gene expression profiles for a given phenotype, in which the disease pathway enrichment results are integrated. Each disease expression profile is preprocessed, and the pathways that show significant differences between case and control samples are identified by GSEA [9], which returns the enrichment score (ES) and nominal $p$ value for each pathway. These scores are used for comparison analysis across pathways to detect significant pathways.

Here, we considered that the integration of pathways significantly enriched for each expression profile could better represent "disease-specific pathways" for the phenotype of interest. To integrate, the pathways with a nominal $p$ value 


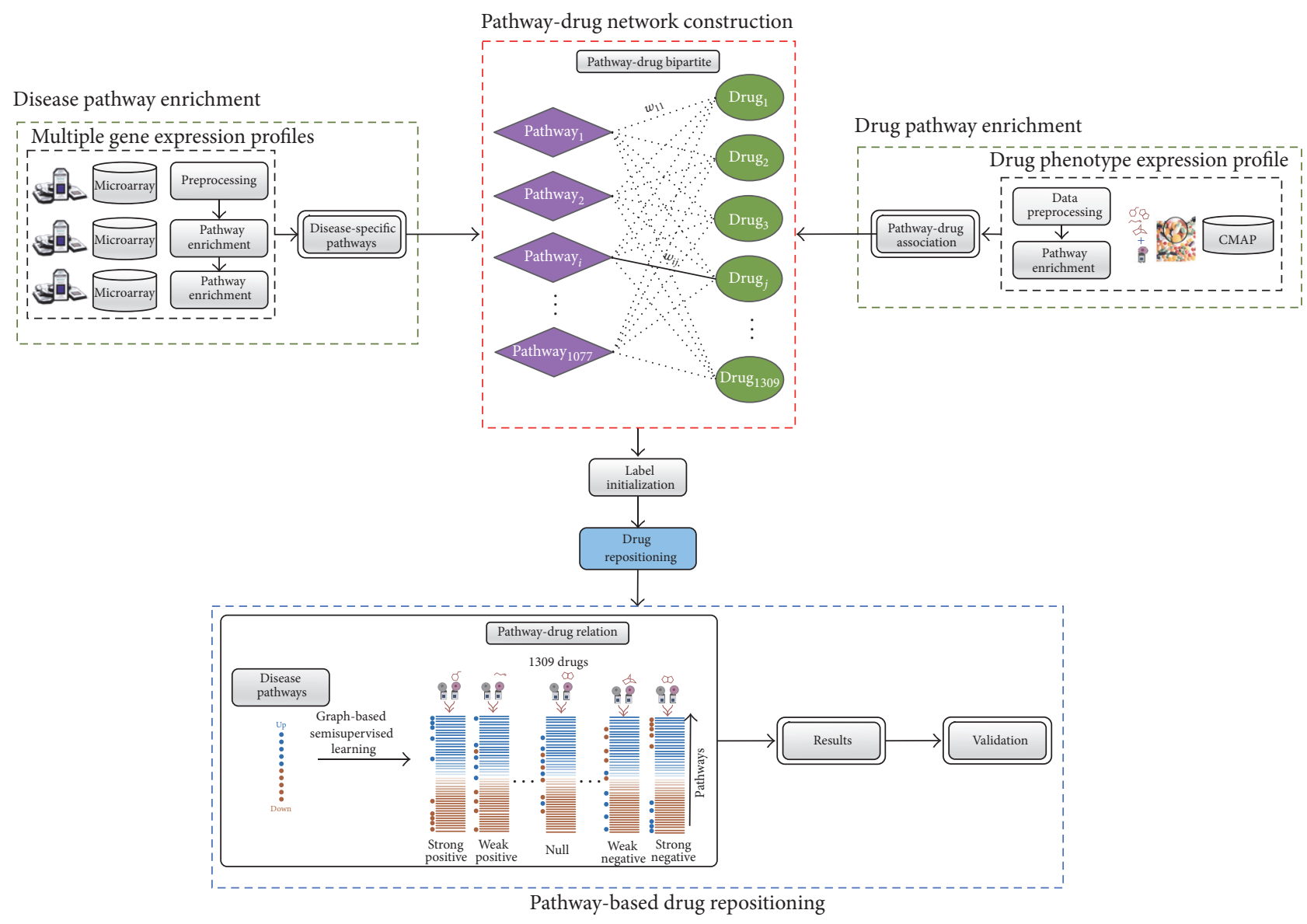

Figure 1: The proposed framework for drug repositioning. The proposed framework consists of several steps. First, disease-specific pathways are identified by disease pathway enrichment of multiple expression profiles for the disease of interest. Second, the drug pathway network is constructed from the drug pathway associations obtained from the drug phenotype profiles. Once the network is constructed, initial labels are assigned using disease-specific pathways and known drugs associated with the given disease. Finally, pathway-based drug repositioning is performed using semisupervised network propagation. The identified drugs are evaluated, and the final results are obtained.

less than $0.01(p<0.01)$ are selected as significant pathways for each expression profile, and their union is defined as "disease-specific pathways." Figure 2 presents an illustration of the integration process.

\subsection{Deriving Pathway-Drug Associations from CMap Drug} Phenotype Profiles. To define a pathway-drug association, pathway-drug enrichment is established from the drug phenotype expression profile (CMap: Connectivity Map) [6, 7], which contains the gene expression profiles obtained from five different cancer cell lines treated with 1309 (v2) small drug molecules, most of which are FDA-approved drugs, for a total 6100 data points representing gene expression results with control vehicle samples. The CMap data are preprocessed, batch effects are removed, and pathway enrichments are estimated by GSEA as in previous studies [11, 26, 27]. As a result, each pathway (1077) has an ES for each drug molecule (1309). The strength of the ES indicates the association degree of a pathway with a drug. As shown in Figure 3, the pathwaydrug association can be represented as a $1077 \times 1309$ matrix, where the columns list the drugs and the rows list the pathways.

2.3. Pathway-Drug Network Construction. A pathway-drug network was established from the drug pathway association profile. By using the pathway-drug enrichment matrix (Figure 3), the pathway-drug bipartite graph structure $G=$ $(U, V, E, w)$ was constructed, whose vertices can be divided into two disjoint sets: $U$ (pathways) and $V$ (drugs) such that every edge $e \in E$ with weight $w$ represents the enrichment of pathway $u_{i} \in U$ by drug $v_{j} \in V$. In other words, each node in the network corresponds to a drug or pathway, and each edge corresponds to the association between them. It can be observed that drugs tend to bind with disease-specific pathways. All nodes were initially unlabeled as 0 . Semisupervised learning on a network requires a small amount of labeled data with a large amount of unlabeled data.

To use the constructed bipartite graph for drug repositioning, we made following assumption as in [4]: If pharmacologically different drugs induce the same phenotype of 


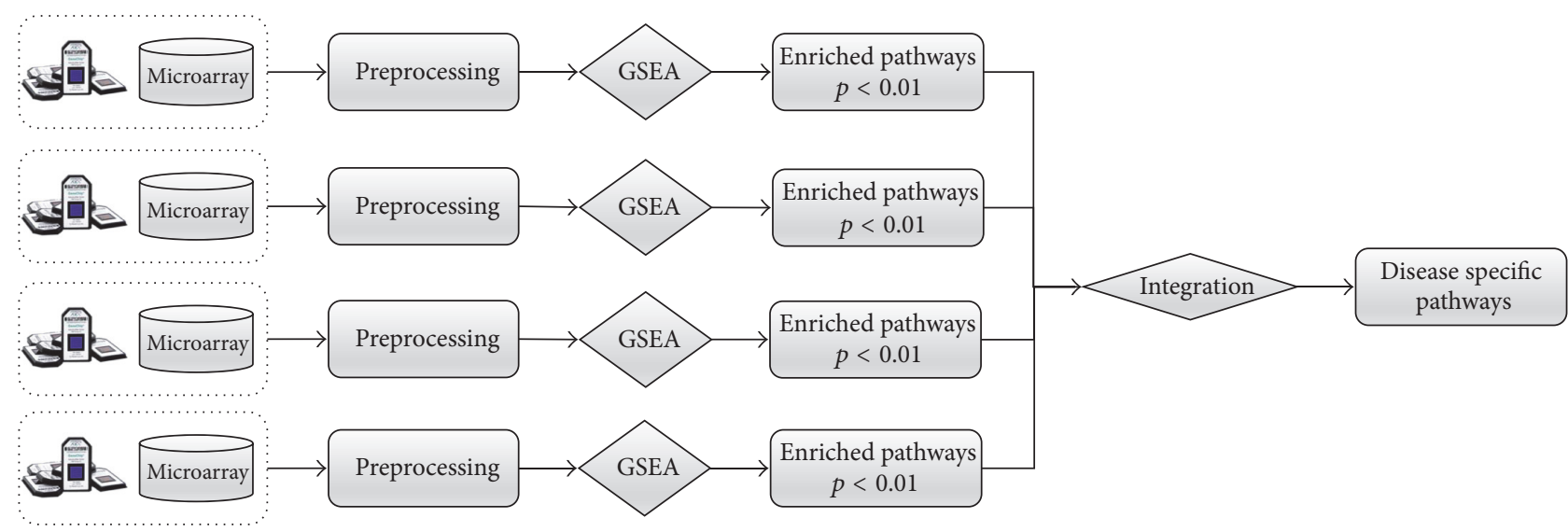

FIGURE 2: Disease pathway enrichment. Disease-specific pathways are identified from multiple gene expression profiles for the same disease. For each profile, enriched pathways with $p<0.01$ are selected and integrated by taking their union. The resulting pathways are considered disease-specific pathways for the given disease.

interest, then most of molecular pathways they target must be shared. In other words, drugs used to treat the same disease (phenotype) target similar pathways. For example, if we have some prior knowledge on certain drugs that are used to treat a specific disease, then most of the molecular pathway they target should be similar. In Figure 4, the blue drugs (breast cancer treatment drugs) target pathway "B," and the green drugs (prostate cancer treatment drugs) target pathway "D." From this information, it is can be concluded that drug " $K$ " can likely be used to treat prostate cancer, when the weight (ES) is high enough. This is main assumption that we make in our proposed framework for pathway-based drug repositioning. Defining the initial knowledge (or initial labels for nodes) is also one of the key steps in this work.

2.4. Label Initialization on a Pathway-Drug Network. To initialize the pathway-drug labels for the $U$ (pathways) and $V$ (drugs) disjoint sets, we used disease-specific pathways inferred from the multiple gene expression profiles and known treatment drugs for the given phenotype (breast cancer) were obtained from three different public resources: the Maya Clinic, Cancer Organization, and TTD. The identified disease-specific pathways were mapped to the $U$ (pathways) set and labeled as 1 , and the remaining pathways were labeled as 0 .

For the $V$ (drugs) set, a more accurate prediction is possible if we can set the labels for the drug set in the pathwaydrug network using previously known information about the disease-related drugs prior to using network propagation to predict drugs associated with the disease. Therefore, we first verified known drugs used for the treatment of the disease of interest using public drug-related sources, including the Maya Clinic database, Cancer Organization database, and TTD, and then determined the labels for the drug set in the pathway-drug network. These drugs were mapped to the $V$ (drugs) set and labeled as 1 , and the remaining drugs were labeled as 0 .
2.5. Drug Repositioning by Semisupervised Learning. Once the initial labeling of the pathway-drug network was completed, we predicted the repositioned drugs by learning the drug nodes and pathway nodes with the network propagation algorithm. The bipartite graph can be defined as $G=$ $(V, U, E, w)$, where $V$ and $U$ are the node sets that are the disjoint node, in which the nodes of each node set are expressed as $v$ and $u$, respectively. $E$ is the set of edges between $V$ and $U$, and $w$ represents the weights of these edges. The weight of a specific edge is expressed as $w(v, u)$. The function for the sum of all weight values for a node can be defined as $d(v)=\sum_{(v, u)} w(v, u)$. Now, let us examine the network propagation algorithm based on the definition of the previously defined bipartite graph. First, the network propagation algorithm normalizes the weights of the bipartite graph using the following formula:

$$
B=D_{v}^{-1 / 2} * W * D_{u}^{-1 / 2} .
$$

Here, $W$ is a matrix containing the weights of the bipartite graph, $D_{v}$ and $D_{u}$ are the diagonal matrices with the values of $D_{i_{v}, i_{v}}=d(v)$ and $D_{i_{u} i_{u}}=d(u)$, respectively, and $B$ is the matrix of the normalized weights. Second, network propagation is performed for the bipartite graph using formulae (2) and (3), iterating over the objective function of the graph-based semisupervised learning algorithm.

For each $v \in V$,

$$
f(v)^{t}=(1-\alpha) y(v)+\alpha \sum_{u \in U} B_{i_{v} i_{u}} f(u)^{t-1} .
$$

For each $u \in U$,

$$
f(u)^{t}=(1-\alpha) y(u)+\alpha \sum_{v \in V} B_{i_{v} i_{u}} f(v)^{t-1} .
$$

Here, $t$ is the number of iterations and $y$ is the initial label of the corresponding node. The parameter $\alpha$ has a value between 0 and 1 and acts to regulate the relative weight of the initial 


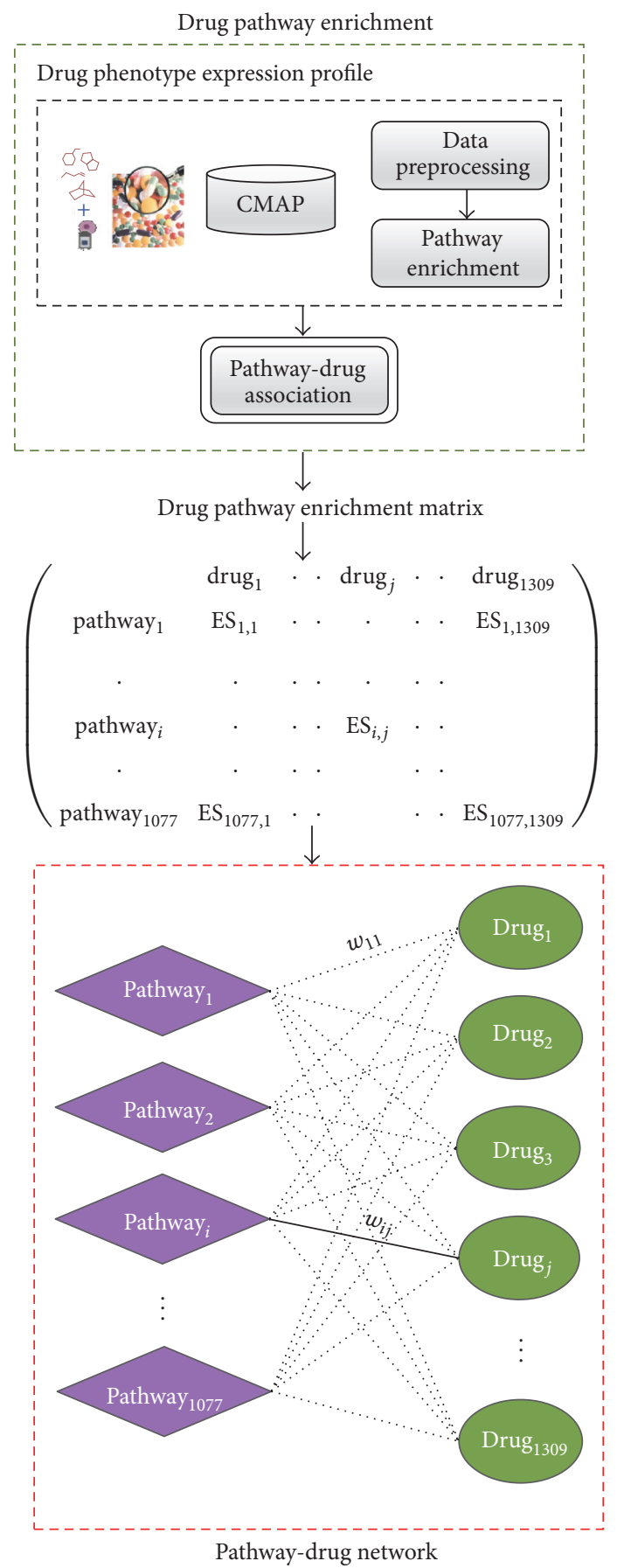

Figure 3: Drug pathway association and pathway-drug network. Associations between a drug and pathways are defined by drug pathway enrichment from drug phenotype expression profiles. The strength of $\mathrm{ES}_{i, j}$ represents the enrichment of pathway ${ }_{j}$ when treated with drug ${ }_{j}$.

label and the learned label. $y(v)$ and $y(u)$ are the initial labels for the drugs and pathway, respectively, whereas $f(v)$ and $f(u)$ are the final label scores. Finally, network propagation is completed when the values of $f(v)$ and $f(u)$ converge.

If the network propagation algorithm is executed over the pathway-drug bipartite according to the above method, the learned drugs label scores can be obtained. As the label score of a drug increases, the drug can be considered a more promising candidate for drug repositioning for the given phenotype. Therefore, we define the values of the final drug label scores as the drug repositioning scores and use them to predict disease-associated drugs from the pathway-drug network. In addition, all obtained label scores are normalized by the $Z$-score using the following equation:

$$
Z_{\mathrm{drug}_{i}}=\frac{l_{\mathrm{drug}_{i}}-\operatorname{mean}(l)}{\operatorname{std}(l)}
$$




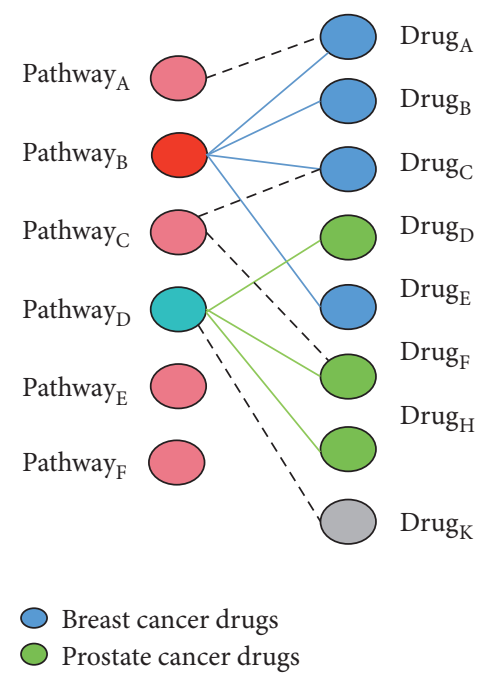

FIGURE 4: Similar drugs used for the same disease share most of the molecular pathway they target.

where $l$ is the label score vector for all drugs and $l_{\operatorname{drug}_{i}}$ is the final label score for drug $_{i}$. For each drug, the corresponding $p$ value was estimated based on the $Z$-score for Gaussian distribution. For more conservative results, we chose drugs with $p<0.001$ as promising drug candidates for drug repositioning for the given disease. The selected promising drug candidates are evaluated by our validation methods and chosen for further investigation.

\section{Results and Discussion}

We tested our proposed framework to reposition 1309 drugs for breast cancer.

3.1. Finding Disease-Specific Pathways in Breast Cancer. To obtain breast cancer-specific pathways, we used publicly available breast cancer expression profiles (GSE15852 [28], GSE20437 [29], GSE2043 [30], and GSE2990 [31]) from the Gene Expression Omnibus (GEO) [32]. Table 1 shows the detailed characteristics of the expression profiles used in our study. Each dataset was preprocessed using RMA techniques [33] and implemented in R using the BioConductor package, which includes a large number of metadata packages appropriate for different types of microarrays. Supplementary Figure 1, in Supplementary Material available online at http://dx.doi.org/10.1155/2016/7147039, shows the results of preprocessing. For each dataset, the corresponding annotation databases were downloaded separately, and each probe was mapped to a HUGO [34] gene symbol; a probe was discarded if it did not match any symbol. In addition, if a gene had multiple probes (many-to-one), the gene expression values were averaged over the probes.

The human metabolic and signaling pathways were obtained from the Molecular Signature Database (MSigDB) [35]. As shown in Table 2, we chose the canonical pathways in the curated gene sets that contain 1077 pathways collected from KEGG [36], Reactome [37], and BioCarta (http://www.biocarta.com/).

For each dataset, a pathway was defined as breast cancer enriched by GSEA when $p<0.01$. To integrate, the enriched pathways with nominal $p$ values less than $0.01(p<0.01)$ were selected as significant pathways for each expression profile, and their union was defined as the "disease-specific pathways." Table 3 shows the number of enriched pathways for each dataset and the integrated pathways obtained by taking their union. Table 4 shows an example of enriched pathways in breast cancer by using experiment dataset (GSE2990). In the Supplementary Material, Tables 1-4 provide the GSEA analysis results for each cancer expression profile and list the identified disease-specific pathways that were used for label initialization on the pathway-drug network.

3.2. Breast Cancer Drug Repositioning Using the Proposed Approach. From the four different breast cancer expression profiles, 143 pathways were identified as significantly enriched. On the pathway-drug network, these pathways were mapped to the $U$ (pathways) set and initially labeled as 1 , and the remaining 934 pathways were labeled as 0 . In addition, known drugs used for the treatment for breast cancer were obtained from three different public resources, the Maya Clinic, Cancer Organization, and TTD. Sixtyone drugs approved to treat breast cancer were obtained from the Maya Clinic, 49 drugs were obtained from the Cancer Organization, and 11 drugs were obtained from TTD. Next, after mapping these drugs to the drug pathway network only 10 drugs were successfully mapped. Moreover, the 10 mapped drugs (tamoxifen, letrozole, doxorubicin, vinblastine, exemestane, aminoglutethimide, methotrexate, paclitaxel, megestrol, and fulvestrant) were labeled as 1 on $V$ (drugs), whereas all remaining drugs (1299) were labeled as 0.

Once the initial labels of the pathway-drug network were chosen, we predicted promising candidates related to breast cancer using semisupervised network propagation, as shown in Figure 5. As a result, we considered 17 drugs with $p<0.001$, as shown in Table 5 , and found that 10 of them are already known drugs. The remaining seven drugs were considered as promising drug candidates for breast cancer and used for further validation to examine their association with breast cancer.

3.3. Validation of Promising Candidate Drugs. To validate the predicted drugs, we recommend the use of two different methods. Drugs that have been successfully validated by both methods are considered to be confirmed for repositioning for breast cancer.

3.3.1. Biological Validation. Biological validation was performed by manually checking the evidence in the biological literature on promising drug candidates. We manually searched for any possible indication of the repositioned drugs for breast cancer. As shown in Table 6, for each promising drug candidate, several different lines of evidence in the literature were found indicating its possible use for breast cancer. Based on these results, we concluded that six drugs of seven drugs were confirmed by biological validation for their new 
TABLE 1: Breast cancer gene expression datasets.

\begin{tabular}{lccccc}
\hline$\#$ & Dataset id & Samples (control/case) & Probes & Platform & References \\
\hline 1 & GSE15852 & $86(43 / 43)$ & 22283 & GPL96 (HG-U133A) & Pau Ni et al. [28] \\
2 & GSE20438 & $42(18 / 26)$ & 22283 & GPL96 (HG-U133A) & Graham et al. [29] \\
3 & GSE2043 & $286(180 / 106)$ & 22283 & GPL96 (HG-U133A) & Wang et al. [30] \\
4 & GSE2929 & $193(64 / 129)$ & 22283 & GPL96 (HG-U133A) & Sotiriou et al. [31] \\
\hline
\end{tabular}

The gene expression datasets were downloaded from the NCBI Gene Expression Omnibus (GEO).

TABLE 2: Pathway data.

\begin{tabular}{lccc}
\hline Database & Pathways & \# of gene sets & URL \\
\hline MSigDB & KEGG & 186 & http://www.genome.jp/kegg/ \\
(c2-canonical & Reactome & 674 & http://www.reactome.org/ \\
pathways) & BioCarta & 217 & http://www.biocarta.com/ \\
\hline Total & & 1077 & \\
\hline
\end{tabular}

TABLE 3: Breast cancer disease-specific pathways for each dataset.

\begin{tabular}{lccccc}
\hline & GSE15852 & GSE20438 & GSE2043 & GSE2929 & $\begin{array}{c}\text { Integrated } \\
\text { pathways }\end{array}$ \\
\hline $\begin{array}{l}\text { \# of pathways } \\
p<0.01\end{array}$ & 109 & 7 & 17 & 21 & $\mathbf{1 4 3}$ \\
\hline
\end{tabular}

Enriched pathways were identified by GSEA. For integration, the pathways with ( $p$ value $<0.01)$ were selected as significant pathways for each expression profile and their union was defined as "disease-specific pathways."

TABLE 4: Breast cancer pathways from GSE2990 ( $p<0.01)$.

\begin{tabular}{|c|c|c|c|c|}
\hline \# & Name & ES & NES & $p$ value \\
\hline 1 & REACTOME_DEFENSINS & -0.767 & -1.599 & 0.008230452 \\
\hline 2 & REACTOME_ORGANIC_CATION_ANION_ZWITTERION_TRANSPORT & 0.771 & 1.668 & 0.004016064 \\
\hline 3 & REACTOME_G0_AND_EARLY_G1 & -0.771 & -1.601 & 0.008213553 \\
\hline 4 & REACTOME_CELL_SURFACE_INTERACTIONS_AT_THE_VASCULAR_WALL & -0.601 & -1.670 & 0 \\
\hline 5 & $\begin{array}{l}\text { REACTOME_SYNTHESIS_OF_BILE_ACIDS_AND_BILE_SALTS_VIA_7ALPHA_ } \\
\text { HYDROXYCHOLESTEROL }\end{array}$ & 0.756 & 1.644 & 0.00617284 \\
\hline 6 & REACTOME_PECAM1_INTERACTIONS & -0.855 & -1.685 & 0.001972387 \\
\hline 7 & REACTOME_GABA_SYNTHESIS_RELEASE_REUPTAKE_AND_DEGRADATION & 0.773 & 1.558 & 0.003891051 \\
\hline 8 & REACTOME_ACTIVATION_OF_THE_PRE_REPLICATIVE_COMPLEX & -0.773 & -1.613 & 0.008438818 \\
\hline 9 & BIOCARTA_GATA3_PATHWAY & 0.746 & 1.688 & 0.002004008 \\
\hline 10 & REACTOME_NEUROTRANSMITTER_RELEASE_CYCLE & 0.709 & 1.747 & 0 \\
\hline 11 & BIOCARTA_G2_PATHWAY & -0.705 & -1.704 & 0.00625 \\
\hline 12 & REACTOME_PASSIVE_TRANSPORT_BY_AQUAPORINS & -0.757 & -1.718 & 0.001865672 \\
\hline 13 & REACTOME_PYRIMIDINE_METABOLISM & -0.702 & -1.726 & 0.001964637 \\
\hline 14 & BIOCARTA_ACTINY_PATHWAY & -0.734 & -1.749 & 0.001945525 \\
\hline 15 & REACTOME_SYNTHESIS_OF_GLYCOSYLPHOSPHATIDYLINOSITOL_GPI & 0.703 & 1.699 & 0.001976285 \\
\hline 16 & REACTOME_ENDOGENOUS_STEROLS & -0.762 & -1.694 & 0.005703422 \\
\hline 17 & REACTOME_GLYCOSPHINGOLIPID_METABOLISM & 0.590 & 1.763 & 0.006048387 \\
\hline
\end{tabular}

Supplementary files 2, 3, 4, and 5 provide the full pathway enrichment analysis results for the breast cancer expression profiles. 
TABLE 5: Predicted drugs after pathway-based drug repositioning.

\begin{tabular}{|c|c|c|c|c|}
\hline Drug name & Ranking score & $Z$-score & $p$ value & Description \\
\hline Doxorubicin* & 0.999 & 8.935 & 0 & $\begin{array}{l}\text { It works by intercalating DNA, with the most serious adverse } \\
\text { effect being life threatening heart damage. }\end{array}$ \\
\hline Exemestane $^{*}$ & 0.803 & 6.880 & $2.99 E-12$ & Tyrosine kinase inhibitor which selectively inhibits HER2 \\
\hline Methotrexate* $^{*}$ & 0.708 & 5.892 & $1.91 E-09$ & $\begin{array}{l}\text { blocks the production of steroids derived from cholesterol and } \\
\text { is clinically used in the treatment of Cushing's syndrome and } \\
\text { metastatic breast cancer. }\end{array}$ \\
\hline Megestrol* $^{*}$ & 0.668 & 5.464 & $2.33 E-08$ & $\begin{array}{l}\text { It binds to and inhibits the enzyme dihydrofolate reductase, } \\
\text { resulting in inhibition of purine nucleotide and thymidylate } \\
\text { synthesis and, subsequently, inhibition of DNA and RNA } \\
\text { syntheses. }\end{array}$ \\
\hline Paclitaxel $^{*}$ & 0.646 & 5.235 & $8.26 E-08$ & $\begin{array}{l}\text { It binds to and stabilizes microtubules, preventing their } \\
\text { depolymerization and so inhibiting cellular motility, mitosis, } \\
\text { and replication. }\end{array}$ \\
\hline Aminoglutethimide* & 0.637 & 5.148 & $1.32 E-07$ & $\begin{array}{l}\text { It blocks the production of steroids derived from cholesterol and } \\
\text { is clinically used in the treatment of Cushing's syndrome and } \\
\text { metastatic breast cancer. }\end{array}$ \\
\hline Tamoxifen* & 0.634 & 5.113 & $1.59 E-07$ & $\begin{array}{l}\text { It is an antagonist of the estrogen receptor in breast tissue via its } \\
\text { active metabolite, hydroxytamoxifen. In other tissues such as } \\
\text { the endometrium, it behaves as an agonist and thus may be } \\
\text { characterized as a mixed agonist/antagonist. }\end{array}$ \\
\hline Vinblastine* & 0.625 & 5.020 & $2.59 E-07$ & $\begin{array}{l}\text { It is an antimicrotubule drug used to treat certain kinds of } \\
\text { cancer, including Hodgkin's lymphoma, non-small cell lung } \\
\text { cancer, breast cancer, head and neck cancer, and testicular } \\
\text { cancer. }\end{array}$ \\
\hline Fulvestrant ${ }^{*}$ & 0.604 & 4.802 & $7.86 E-07$ & $\begin{array}{l}\text { It is drug treatment of hormone receptor-positive metastatic } \\
\text { breast cancer in postmenopausal women with disease } \\
\text { progression following antiestrogen therapy. It is an estrogen } \\
\text { receptor antagonist with no agonist effects, which works by } \\
\text { downregulating the estrogen receptor. }\end{array}$ \\
\hline Letrozole $^{*}$ & 0.579 & 4.539 & $2.83 E-06$ & $\begin{array}{l}\text { It is an oral nonsteroidal aromatase inhibitor for the treatment } \\
\text { of hormonally responsive breast cancer. }\end{array}$ \\
\hline MS-275** & 0.530 & 4.023 & $2.87 E-05$ & $\begin{array}{l}\text { Entinostat, also known as SNDX-275 and MS-275, is a } \\
\text { benzamide histone deacetylase inhibitor undergoing clinical } \\
\text { trials for treatment of various cancers. }\end{array}$ \\
\hline GW-8510** & 0.477 & 3.467 & 0.000263332 & $\begin{array}{l}\text { Cyclin-dependent kinase } 5 \text { inhibitors: inhibition of dopamine } \\
\text { transporter activity. }\end{array}$ \\
\hline Camptothecin** & 0.475 & 3.452 & 0.000278495 & $\begin{array}{l}\text { It is an alkaloid isolated from the stem wood of the Chinese tree, } \\
\text { Camptotheca acuminata. This compound selectively inhibits the } \\
\text { nuclear enzyme DNA topoisomerase. }\end{array}$ \\
\hline Phenoxybenzamine ${ }^{* *}$ & 0.461 & 3.303 & 0.000478379 & $\begin{array}{l}\text { It is an alpha-adrenergic antagonist with long duration of } \\
\text { action. It has been used to treat hypertension and as a peripheral } \\
\text { vasodilator. }\end{array}$ \\
\hline Tyrphostin_AG-825** & 0.447 & 3.159 & 0.000792504 & It is tyrosine kinase inhibitor, which selectively inhibits HER2. \\
\hline Alsterpaullone** & 0.447 & 3.150 & 0.000815292 & $\begin{array}{l}\text { CDC2 protein kinase, antiangiogenic potential of small } \\
\text { molecular inhibitors of cyclin-dependent kinases in vitro. }\end{array}$ \\
\hline Celastrol $^{* *}$ & 0.442 & 3.100 & 0.000966191 & $\begin{array}{l}\text { Celastrol is a remedial ingredient isolated from the root extracts } \\
\text { of "Tripterygium wilfordii" (Thunder of God vine) and } \\
\text { "Celastrus regelii." In "in vitro" and "in vivo" animal } \\
\text { experiments, celastrol exhibits antioxidant, anti-inflammatory, } \\
\text { anticancer, and insecticidal activities. }\end{array}$ \\
\hline
\end{tabular}

${ }^{*}$ Known breast cancer drug. ${ }^{* *}$ Potential drug candidate for repositioning. 
TABLE 6: Literature evidences for the promising drug candidates for breast cancer.

\begin{tabular}{|c|c|c|}
\hline Promising drugs & $\begin{array}{l}\text { Biological } \\
\text { validation }\end{array}$ & Related literature for possible usage for breast cancer \\
\hline MS-275** & $\mathbf{o}$ & $\begin{array}{l}\text { (i) [45]: the potential anticancer activity of MS-275 in combination with } \\
\text { pentoxifylline in panel of cell lines and human breast cancer xenograft model in } \\
\text { vitro and in vivo. } \\
\text { (ii) [46]: MS-275 sensitizes TRAIL-resistant breast cancer cells, inhibits } \\
\text { angiogenesis and metastasis, and reverses epithelial-mesenchymal transition in vivo. } \\
\text { (iii) [47]: HDAC inhibitors (MS-275) enhance the apoptosis-inducing potential of } \\
\text { TRAIL in breast carcinoma. }\end{array}$ \\
\hline GW-8510** & $\diamond$ & $\begin{array}{l}\text { (i) [48]: repositioning of a cyclin-dependent kinase inhibitor GW-8510 as a } \\
\text { ribonucleotide reductase } \mathrm{M} 2 \text { inhibitor to treat human colorectal cancer. In addition, } \\
\text { GW-8510 induced autophagic cell death. } \\
\text { (ii) [49]: in cell viability tests, four candidate drugs, GW-8510, etacrynic acid, } \\
\text { ginkgolide A, and 6-azathymine, are identified as having high inhibitory activities } \\
\text { against cancer cells. }\end{array}$ \\
\hline Camptothecin ${ }^{* *}$ & $\mathbf{o}$ & $\begin{array}{l}\text { (i) [50]: the camptothecin targets WRN protein: mechanism and relevance in } \\
\text { clinical breast cancer. } \\
\text { (ii) [51]: CRLX101, an investigational camptothecin-containing nanoparticle-drug } \\
\text { conjugate, targets cancer stem cells and impedes resistance to antiangiogenic } \\
\text { therapy in mouse models of breast cancer. } \\
\text { (iii) [52]: STI571 sensitizes breast cancer cells to 5-fluorouracil, cisplatin, and } \\
\text { camptothecin in a cell type-specific manner. } \\
\text { (iv) [53]: acquired camptothecin resistance of human breast cancer MCF-7/C4 cells } \\
\text { with normal topoisomerase I and elevated DNA repair. } \\
\text { (v) known as "Happy Tree" in Chinese traditional cancer treatment. }\end{array}$ \\
\hline Phenoxybenzamine ${ }^{* *}$ & $\mathbf{x}$ & (i) Not enough evidence. \\
\hline Tyrphostin_AG-825** & $\mathbf{o}$ & $\begin{array}{l}\text { (i) [54]: C-Src activation by ErbB2 leads to attachment-independent growth of } \\
\text { human breast epithelial cells. } \\
\text { (ii) [55]: using in vivo mouse models of breast cancer: using gefitinib, ERBB1 } \\
\text { inhibition rapidly inhibits tumor cell motility and invasion but not intravasation, } \\
\text { whereas ERBB2 inhibition by AG825 rapidly blocks intravasation. } \\
\text { (iii) [56]: tyrphostin AG } 825 \text { has been used in combination with } \\
\text { hypericin-mediated photodynamic therapy (HY-PDT) for evaluating its therapeutic } \\
\text { effects in HER2 overexpressing human breast cancer cells. }\end{array}$ \\
\hline Alsterpaullone $e^{* *}$ & $\mathbf{o}$ & $\begin{array}{l}\text { (i) [57]: the antitumor effects of ALP through induction of apoptosis in breast } \\
\text { cancer and leukemia cells. Identification of alsterpaullone as a novel small molecule } \\
\text { inhibitor to target group } 3 \text { medulloblastoma. } \\
\text { (ii) [58]: baicalein blocked survivin expression in lung and breast cancer cells. } \\
\text { Alsterpaullone is a CDC2 kinase inhibitor (43). Both CDC25 phosphatase and } \\
\text { CDC2 kinase inhibitors enhanced the baicalein-induced cancer cell death. }\end{array}$ \\
\hline Celastrol $^{* *}$ & $\mathbf{o}$ & $\begin{array}{l}\text { (i) [59]: anticancer effect of celastrol on human triple negative breast cancer: } \\
\text { possible involvement of oxidative stress, mitochondrial dysfunction, apoptosis, and } \\
\text { PI3K/Akt pathways. } \\
\text { (ii) [60]: celastrol induces that apoptosis of breast cancer cells and inhibits invasion } \\
\text { via downregulation of MMP-9. }\end{array}$ \\
\hline
\end{tabular}

${ }^{* *}$ Potential drug candidate for repositioning.

usage in breast cancer treatment, with phenoxybenzamine not being confirmed.

\subsubsection{Computational Evaluation on the Validation Network.} In drug repositioning, it is difficult to compare and evaluate the performances of computational methods. To address this issue, several recent studies have focused on curating a comprehensive and public catalog of existing drug indications using a manual process [4].
Therefore, to develop a better evaluation method using computational methods, a validation network was constructed using information on three different relationships, drug-drug, drug-gene, and gene-gene, from the STITCH and STRING databases [38]. The drug-drug relationship information was obtained from the STITCH (v4) [39] database, which contains data on the interactions between small molecules and the edges between two chemicals that are expressed using a score between 0 and 900 defined 
TABLE 7: Degree centrality of promising drug candidates on the validation network.

\begin{tabular}{lcc}
\hline Rank & Drug name & $\begin{array}{c}\text { Degree } \\
\text { centrality }\end{array}$ \\
\hline 1 & Tamoxifen $^{*}$ & 0.661 \\
2 & Doxorubicin $^{*}$ & 0.554 \\
3 & Paclitaxel $^{*}$ & 0.536 \\
4 & Fulvestrant $^{*}$ & 0.268 \\
5 & Methotrexate $^{*}$ & 0.268 \\
6 & Camptothecin $^{* *}$ & 0.232 \\
7 & Letrozole $^{*}$ & 0.214 \\
8 & Vinblastine $^{*}$ & 0.196 \\
9 & Exemestane $^{*}$ & 0.179 \\
10 & Megestrol $^{*}$ & 0.125 \\
11 & Aminoglutethimide* $^{*}$ & 0.107 \\
12 & MS-275 $^{* *}$ & 0.089 \\
13 & Alsterpaullone** $^{* *}$ & 0.071 \\
14 & GW-8510 $^{* *}$ & 0.036 \\
15 & Phenoxybenzamine $^{* *}$ & 0.036 \\
16 & Celastrol $^{* *}$ & 0.036 \\
17 & Tyrphostin_AG-825 $^{* *}$ & 0.018 \\
\hline
\end{tabular}

${ }^{*}$ Known breast cancer drug. ${ }^{* *}$ Potential drug candidate for repositioning.

from the chemical similarity between drugs. The drug-gene network was constructed from STITCH (for human) proteinchemical interactions with the help of the STRING database which provides 4,523,609 relationships for humans with the correlations between proteins and chemicals recorded as scores using information obtained from experimental results, text-mining, or predicted correlations. The gene-gene network was constructed from the STRING database, where A PPI network can be described as a complex system of proteins linked by interactions. Two proteins or genes that physically interact are represented as adjacent nodes connected by an edge. Each protein id (unipro id) is converted to the corresponding gene symbols using annotation databases provided in the STRING protein-protein interaction database. For computational evaluation, we have selected a maximum of 40 neighbors of drugs (17 drugs) with a weight criterion of $r>0.4$ from the validation network derived from STITCH. The constructed validation network is illustrated in Figure 6.

To investigate the node properties in a network, network topology measurements (degree centrality and betweenness) and linkage analysis (PageRank) are often used. Degree centrality represents the number of interactions/edges/connections for a node. Biological networks are mostly scalefree networks, in which most nodes have few edges and a small number of nodes (hub) have a very high degree centrality. Betweenness is measured by the shortest paths between all nodes in the network and nodes that have the "shortest path" going through them are called bottlenecks. These hub and bottleneck nodes are topologically important and are usually functionally essential nodes (genes and drugs that have significant biological roles). Nodes connected to the hub and bottleneck node directly can also be functionally important. In addition, link analysis is a technique used to evaluate relationships (connection weights). The PageRank is a popular link analysis algorithm based on idea that a node should be significant if other significant nodes contain links to it.

By answering the following biological questions for the promising drug candidates, we identified the most promising drugs among them.

(i) Which candidate drug has an interesting/important relationship (connections) with known drugs?

(ii) Which candidate drug has the hub/bottleneck property on the validation network?

(iii) Which candidate drugs are connected to known breast cancer target genes?

For this purpose, we checked the network properties of promising drug candidates on the validation network using degree centrality, betweenness, and PageRank. Among them, the network topology measurements (degree centrality and betweenness) are designed to produce a ranking which allows indication of the most important vertices and not designed to measure the influence of neighbor nodes in general. Therefore, for better validation of promising candidates on validation network, PageRank algorithm seems to be more preferable which evaluates the nodes by considering their connection weights to the influential neighbors nodes.

From the results shown in Table 7, the popular breast cancer drug "tamoxifen" was identified as the most important hub node with degree centrality of 0.661 on the validation network. Among the promising drug candidates, camptothecin showed the hub node property with the highest degree centrality (0.232) among the other five (MS275 , GW-8510, phenoxybenzamine, tyrphostin_AG-825, and alsterpaullone). Table 8 shows the neighbor nodes of the camptothecin on the validation network where it has a strong chemical similarity with the known drugs doxorubicin, paclitaxel, vinblastine, and methotrexate. A close look at this relationship is shown in Figure 7(a), and this evidence seems to point to the possibility of using the camptothecin for breast cancer treatment because structurally similar drugs usually bind the same disease targets. In addition, from Table 8 and Figures 7(a) and 7(b), it can be seen that camptothecin has a strong target relation with the genes that play active role in breast cancer including TOP1, ABCB1, TOP2A, CASP3, and TP53 (neighbors) and EGFR (second-degree neighbor). TOP1 and TOP2A were reported to inhibit the breast cancer resistant proteins [40]. ABCB1 is known as prognostic factor in breast cancer patients [41]. CASP3 expression loss represents an important cell survival mechanism in breast cancer patients [42] and it inhibits the growth of breast cancer cells. EGFR was one of the first identified important targets in breast cancer, and half of breast cancer cases overexpress EGFR.

The candidate drugs MS-257 and alsterpaullone showed relatively higher degree centrality values among the remaining drugs. Table 9 and Figure 8 show the neighbor nodes relationship of MS-257 on the validation network, where it 
TABLE 8: The neighbors of candidate drug "camptothecin" on the validation network.

\begin{tabular}{|c|c|c|}
\hline Nodes & Description & Weight \\
\hline TOP1 & $\begin{array}{l}\text { Topoisomerase (DNA) I: the reaction catalyzed by topoisomerases leads to the } \\
\text { conversion of one topological isomer of DNA to another. }\end{array}$ & 0.999 \\
\hline CASP3 & $\begin{array}{l}\text { Caspase 3: apoptosis-related cysteine peptidase: it is involved in the activation } \\
\text { cascade of caspases responsible for apoptosis execution. }\end{array}$ & 0.965 \\
\hline TP53 & $\begin{array}{l}\text { Tumor protein p53: it acts as a tumor suppressor in many tumor types and induces } \\
\text { growth arrest or apoptosis depending on the physiological circumstances and cell } \\
\text { type. }\end{array}$ & 0.965 \\
\hline Doxorubicin ${ }^{*}$ & $\begin{array}{l}\text { It is a drug used in cancer chemotherapy; it works by intercalating DNA, with the } \\
\text { most serious adverse effect being life threatening heart damage. }\end{array}$ & 0.890 \\
\hline ABCG2 & $\begin{array}{l}\text { ATP-binding cassette, subfamily G (WHITE), member } 2 \text {; xenobiotic transporter that } \\
\text { may play an important role in the exclusion of xenobiotics from the brain. It may be } \\
\text { involved in brain-to-blood efflux. It appears to play a major role in the multidrug } \\
\text { resistance phenotype of several cancer cell lines. }\end{array}$ & 0.873 \\
\hline CDK1 & $\begin{array}{l}\text { Cyclin-dependent kinase 1: it plays a key role in the control of the eukaryotic cell } \\
\text { cycle. It is required in higher cells for entry into S phase and mitosis. p34 is a } \\
\text { component of the kinase complex that phosphorylates the repetitive C-terminus of } \\
\text { RNA polymerase II. }\end{array}$ & 0.846 \\
\hline $\mathrm{ABCB} 1$ & $\begin{array}{l}\text { ATP-binding cassette, subfamily B (MDR/TAP), member 1; energy-dependent efflux } \\
\text { pump responsible for decreased drug accumulation in multidrug-resistant cells. }\end{array}$ & 0.843 \\
\hline BCL2 & $\begin{array}{l}\text { B-cell CLL/lymphoma 2: it suppresses apoptosis in a variety of cell systems including } \\
\text { factor-dependent lymphohematopoietic and neural cells. It regulates cell death by } \\
\text { controlling the mitochondrial membrane permeability. It appears to function in a } \\
\text { feedback loop system with caspases. It inhibits caspase activity either by preventing } \\
\text { the release of cytochrome c from the mitochondria and/or by binding to the } \\
\text { apoptosis-activating factor (APAF-1). }\end{array}$ & 0.820 \\
\hline Paclitaxel $^{*}$ & $\begin{array}{l}\text { It binds to and inhibits the enzyme dihydrofolate reductase, resulting in inhibition of } \\
\text { purine nucleotide and thymidylate synthesis and, subsequently, inhibition of DNA } \\
\text { and RNA syntheses. }\end{array}$ & 0.812 \\
\hline CDK2 & $\begin{array}{l}\text { Cyclin-dependent kinase 2; involved in the control of the cell cycle; interacting with } \\
\text { cyclins A, B1, B3, D, or E. Activity of CDK2 is maximal during S phase and G2. }\end{array}$ & 0.754 \\
\hline Vinblastine $^{*}$ & $\begin{array}{l}\text { An antimicrotubule drug used to treat certain kinds of cancer, including Hodgkin's } \\
\text { lymphoma, non-small cell lung cancer, breast cancer, head and neck cancer, and } \\
\text { testicular cancer. }\end{array}$ & 0.560 \\
\hline Methotrexate $^{*}$ & $\begin{array}{l}\text { It blocks the production of steroids derived from cholesterol and is clinically used in } \\
\text { the treatment of Cushing's syndrome and metastatic breast cancer. }\end{array}$ & 0.554 \\
\hline TOP2A & $\begin{array}{l}\text { Topoisomerase (DNA) II alpha } 170 \mathrm{kDa} \text {; control of topological states of DNA by } \\
\text { transient breakage and subsequent rejoining of DNA strands. }\end{array}$ & 0.431 \\
\hline
\end{tabular}

*Known breast cancer drug.

TABLE 9: The neighbors of candidate drug "MS-257" on the validation network.

\begin{tabular}{|c|c|c|}
\hline Genes & Description & Weight \\
\hline HDAC1 & $\begin{array}{l}\text { Histone deacetylase 1; responsible for the deacetylation of lysine residues on the } \mathrm{N} \text {-terminal part of the } \\
\text { core histones }(\mathrm{H} 2 \mathrm{~A}, \mathrm{H} 2 \mathrm{~B}, \mathrm{H} 3 \text {, and } \mathrm{H} 4) \text {. Histone deacetylation gives a tag for epigenetic repression and } \\
\text { plays an important role in transcriptional regulation, cell cycle progression, and developmental events. }\end{array}$ & 0.987 \\
\hline TP53 & $\begin{array}{l}\text { Tumor protein p53: it acts as a tumor suppressor in many tumor types and induces growth arrest or } \\
\text { apoptosis depending on the physiological circumstances and cell type. }\end{array}$ & 0.831 \\
\hline CASP3 & $\begin{array}{l}\text { Caspase } 3 \text {, apoptosis-related cysteine peptidase; involved in the activation cascade of caspases responsible } \\
\text { for apoptosis execution. }\end{array}$ & 0.827 \\
\hline CCND1 & cyclin D1; essential for the control of the cell cycle at the G1/S (start) transition. & 0.822 \\
\hline CYP3A4 & $\begin{array}{l}\text { Cytochrome P } 450 \text {, family } 3 \text {, subfamily A, polypeptide } 4 \text {; cytochromes } \mathrm{P} 450 \text { are a group of heme-thiolate } \\
\text { monooxygenases. }\end{array}$ & 0.433 \\
\hline
\end{tabular}




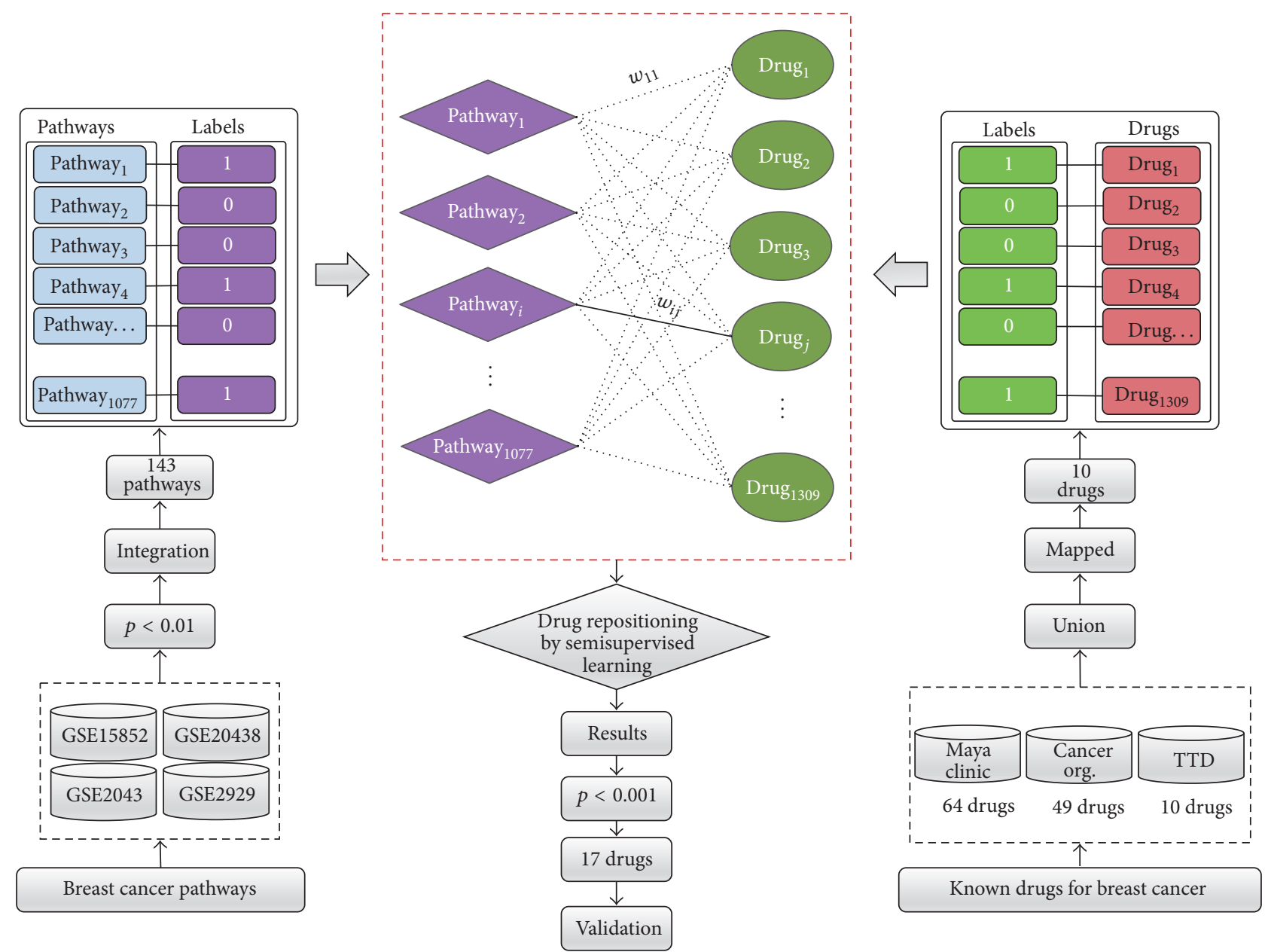

Figure 5: Breast cancer drug repositioning. Ten known drugs approved to treat breast cancer were obtained from the Maya Clinic, Cancer Org, and TTD. A total of 143 breast cancer-specific pathways were identified from multiple breast cancer expression profiles. Successfully mapped pathways and drugs were labeled as 1 . Once labels were initialized on the pathway-drug network, we repositioned drugs for breast cancer using semisupervised learning. Predicted drugs with $p<0.001$ were considered promising candidate drugs, and their associations with breast cancer were investigated using two different validation methods.

has strong target relationships with the genes HDAC1, TP53, CASP3, CCND1, and CYP3A4. Overexpression of HDCA1 represents clinicopathological indicators of disease progression in human breast cancer [43]. CCDN1 was reported to be a therapeutic target in breast cancer [44], and it has an indirect relationship with breast cancer susceptibility gene BRCA1. The betweenness results are summarized in Table 10 . Among promising drug candidates only camptothecin and MS-275 showed some bottleneck node properties. Tamoxifen was defined as the most important bottleneck drug for breast cancer. Finally, we evaluated the connection weights of candidate drugs on the validation network using PageRank algorithm. We chose the alpha parameter as 0.85 , which is the most commonly used value for this parameter with original Google PageRank algorithm. As shown in Table 11, camptothecin (0.257), alsterpaullone (0.102), and MS-275 $(0,088)$ exhibited higher ranking scores than the other promising candidate drugs.

From the evidences shown above, we concluded that camptothecin, MS-257, and alsterpaullone exhibited the strongest network property evidences for breast cancer on the validation network. In general, all of the promising candidates successfully passed the computational evaluation on the network.

After performing biological and computational evaluations of the promising candidate drugs, we selected camptothecin as the most promising candidate because it was the most successful in both evaluation processes. For MS278, GW-85, AG825, alsterpaullone, and celastrol, there was strong literature evidence with a reasonable network property. Thus, as shown in Figure 9, camptothecin, MS-278, alsterpaullone, GW-85, and AG825 and were validated as repositioned drugs and indicated for further investigation in breast cancer treatment.

\section{Summary}

We introduced a new systematic framework for diseasespecific drug repositioning from integrated gene expression profiles on a pathway-drug network constructed from drug 


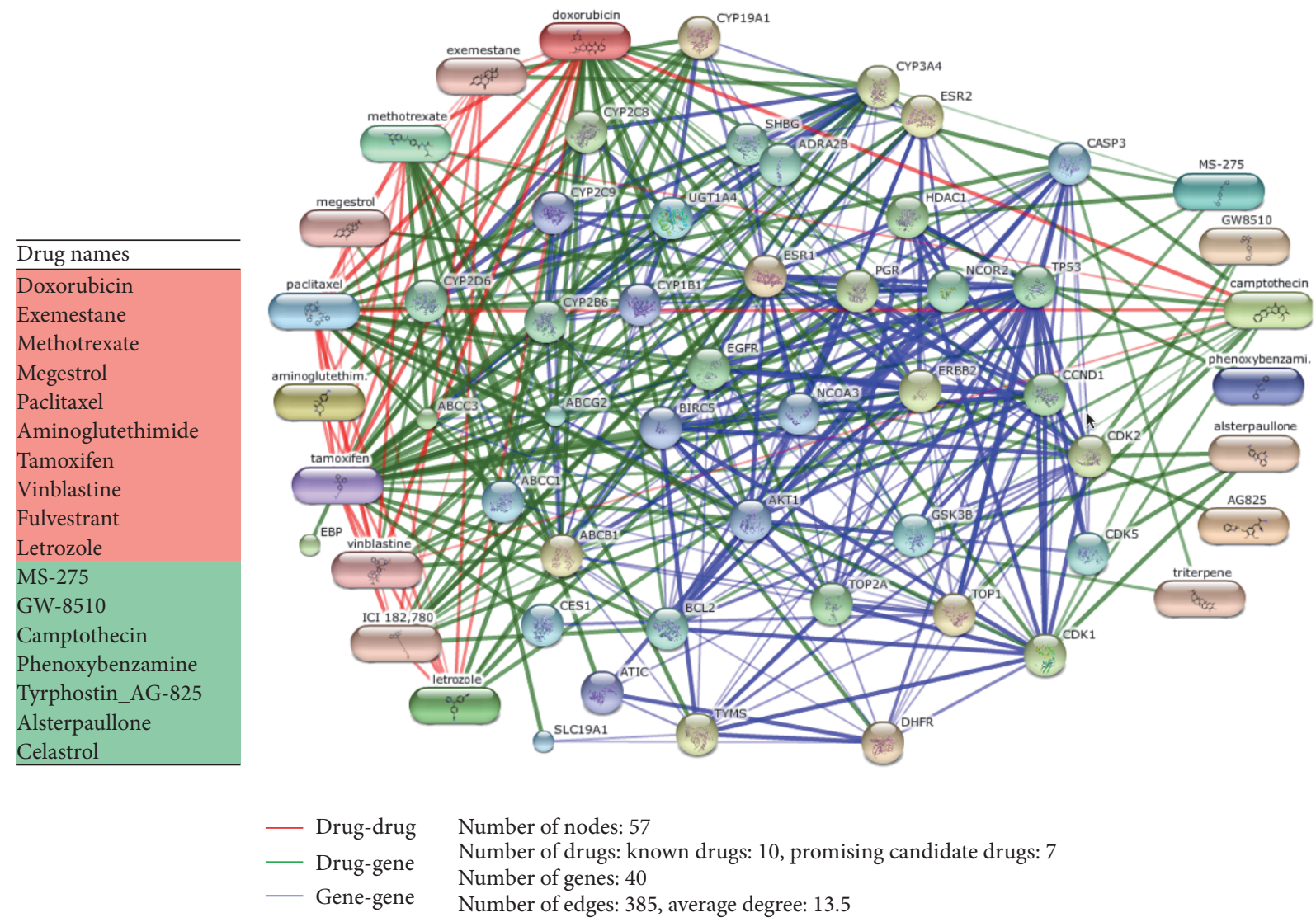

FIGURE 6: Known drugs and promising drug candidates on the validation network. The validation network for 16 drugs was constructed from STITCH. Each node is a drug or a gene. The green edges represent drug-gene interactions, and the red edges indicate drug-drug interactions; the blue edges represent gene-gene relationships obtained from STRING. Wider edges reflect stronger relationships between nodes. For easier implementation and visualization, a maximum of 40 neighbors of drugs (17 nodes) with a weight criterion of $r>0.4$ were selected. As indicated in the figure, some drugs have significant topological features on the validation network.

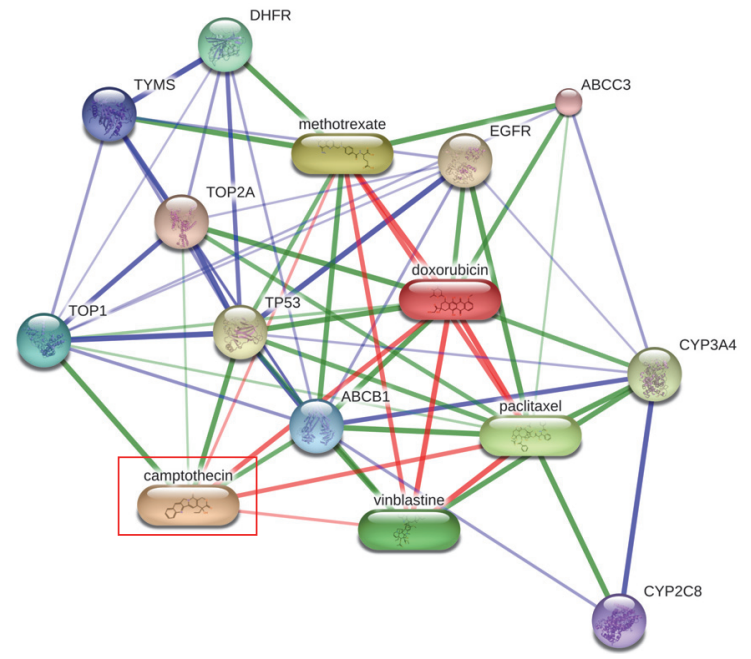

(a)

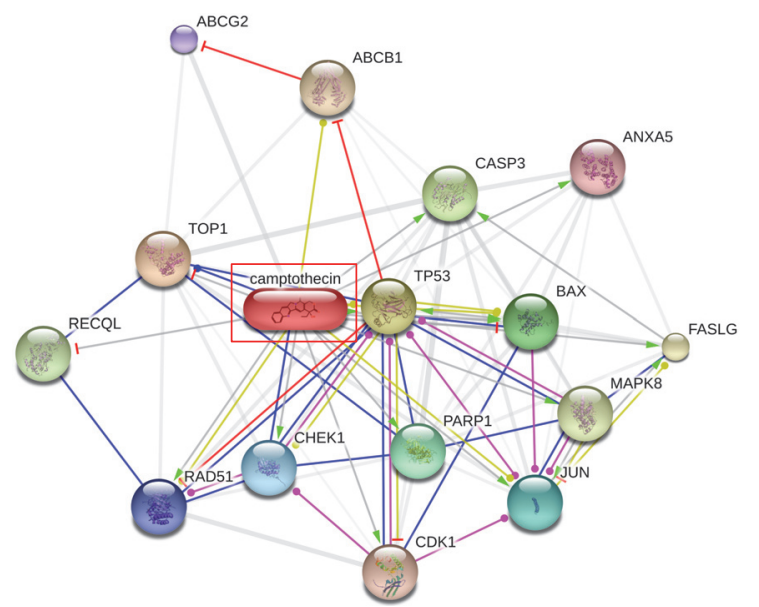

(b)

FIgURE 7: The candidate drug camptothecin on the validation network. (a) Camptothecin has a strong relationship (chemical similarity) with known breast cancer drugs: doxorubin, paclitaxel, vinblastine, and methotrexate. (b) Camptothecin has direct target relationship with the genes playing active roles in breast cancer including TOP1, ABCB1, TOP2A, CASP3, and TP53 (neighbors). Moreover, it has an indirect relationship with the breast cancer target gene EGFR. 


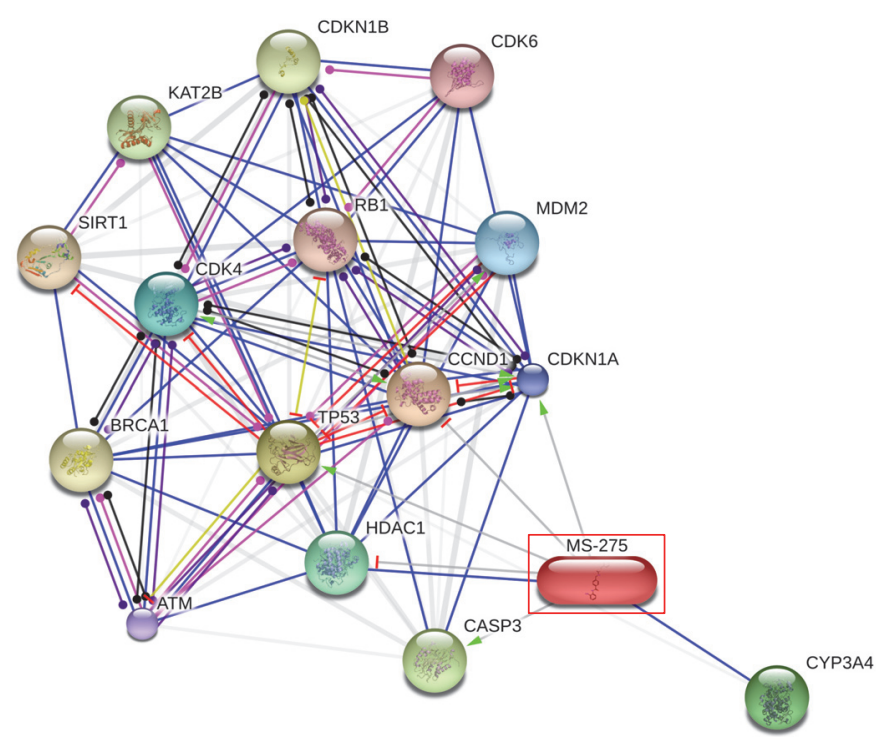

Directly connected genes

\begin{tabular}{|c|c|c|}
\hline Genes & Description & Weight \\
\hline HDAC1 & $\begin{array}{l}\text { Histone deacetylase } 1 \text {; responsible for the deacetylation of lysine residues on the } \mathrm{N} \text { - } \\
\text { terminal part of the core histones }(\mathrm{H} 2 \mathrm{~A}, \mathrm{H} 2 \mathrm{~B}, \mathrm{H} 3 \text {, and } \mathrm{H} 4) \text {. Histone deacetylation gives a } \\
\text { tag for epigenetic repression and plays an important role in transcriptional regulation, cell } \\
\text { cycle progression, and developmental events }\end{array}$ & 0.987 \\
\hline TP53 & $\begin{array}{l}\text { Tumor protein p53; it acts as a tumor suppressor in many tumor types; it induces growth } \\
\text { arrest or apoptosis depending on the physiological circumstances and cell type }\end{array}$ & 0.831 \\
\hline CASP3 & $\begin{array}{l}\text { Caspase 3, apoptosis-related cysteine peptidase; it is involved in the activation cascade of } \\
\text { caspases responsible for apoptosis execution }\end{array}$ & 0.827 \\
\hline CCND1 & Cyclin D1: it is essential for the control of the cell cycle at the G1/S (start) transition & 0.822 \\
\hline CYP3A4 & $\begin{array}{l}\text { Cytochrome P450, family } 3 \text {, subfamily A, polypeptide } 4 \text {; cytochromes P450 are a group of } \\
\text { heme-thiolate monooxygenases }\end{array}$ & 0.433 \\
\hline
\end{tabular}

Neighbor genes

\begin{tabular}{|c|c|c|}
\hline Genes & Description & Weight \\
\hline CDK4 & Cyclin-dependent kinase; probably involved in the control of the cell cycle & 0.999 \\
\hline MDM2 & mdm2 p53 binding protein homolog (mouse), inhibiting TP53/p53 and TP73/p73 cell cycle & 0.999 \\
\hline CDKN1A & $\begin{array}{l}\text { Cyclin-dependent kinase inhibitor } 1 \mathrm{~A}(\mathrm{p} 21, \mathrm{Cip} 1) \text {, whose role is mediated by } \mathrm{p} 53 / \mathrm{TP} 53 \text { as an } \\
\text { inhibitor of cellular proliferation in response to DNA damage }\end{array}$ & 0.999 \\
\hline ATM & Ataxia telangiectasia mutated; serine/threonine protein kinase & 0.999 \\
\hline CDK6 & Cyclin-dependent kinase 6; probably involving the control of cell & 0.999 \\
\hline RB1 & Retinoblastoma 1; key regulator of entry into cell division that acts as a tumor suppressor & 0.999 \\
\hline SIRT1 & $\begin{array}{c}\text { Sirtuin (silent mating type information regulation } 2 \text { homolog) } 1 \text { (S. cerevisiae); NAD- } \\
\text { dependent }\end{array}$ & 0.999 \\
\hline BRCA1 & $\begin{array}{c}\text { Breast cancer 1, early onset; the BRCA1-BARD1 heterodimer coordinates a diverse range } \\
\text { of cell pathways such as DNA damage repair, ubiquitination, and transcriptional regulation } \\
\text { to maintain genomic stability }\end{array}$ & 0.999 \\
\hline CDKN1B & Cyclin-dependent kinase inhibitor 1B (p2, Kip1); important regulator of cell cycle progression & 0.999 \\
\hline КАТ2B & $\begin{array}{c}\mathrm{K} \text { (lysine) acetyltransferase 2B; it has histone acetyl transferase activity with core histones } \\
\text { and nucleosome core particles }\end{array}$ & 0.999 \\
\hline
\end{tabular}




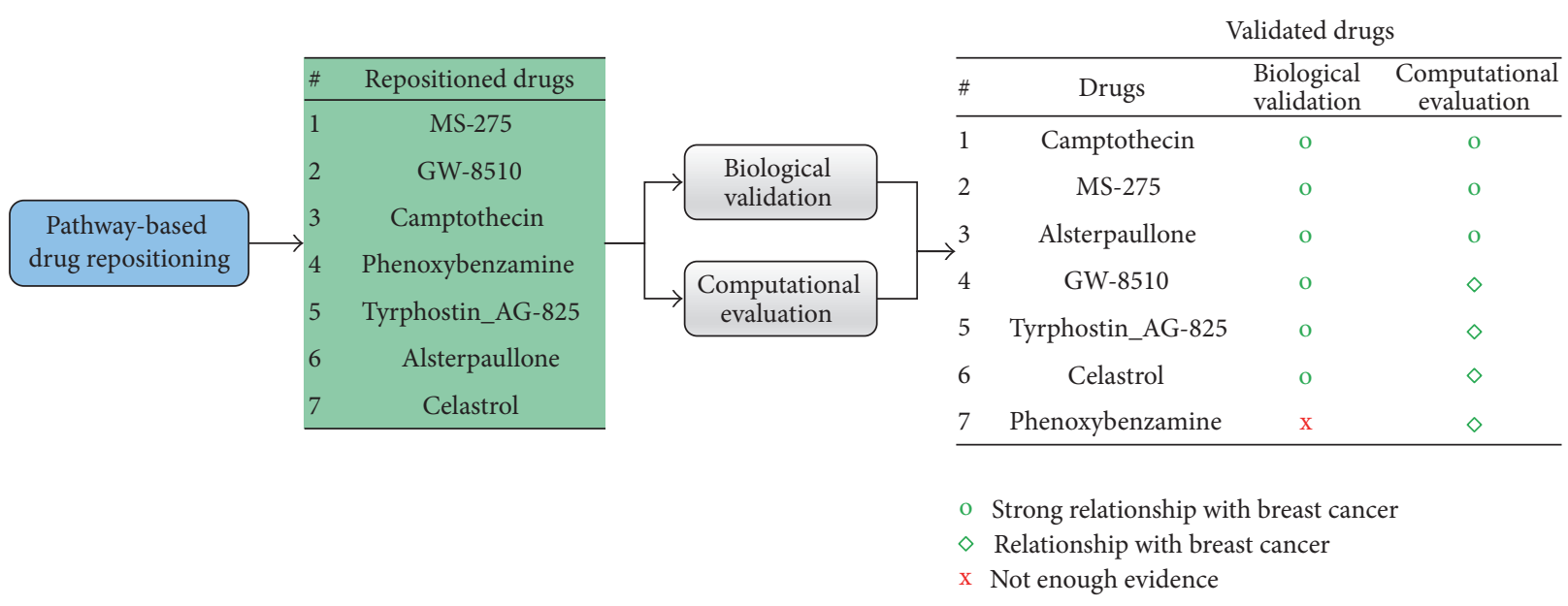

Figure 9: Validated drugs. Candidate drugs with successful results for both the biological validation and computational evaluation are considered repositioned drugs for breast cancer.

TABLE 10: Betweenness of promising drug candidates on the validation network.

\begin{tabular}{lcc}
\hline Rank & Drug name & Betweenness \\
\hline 1 & Tamoxifen* $^{*}$ & 172 \\
2 & Paclitaxel $^{*}$ & 37 \\
3 & Doxorubicin $^{*}$ & 32 \\
4 & Camptothecin $^{* *}$ & 13 \\
5 & Exemestane $^{*}$ & 13 \\
6 & Fulvestrant $^{*}$ & 12 \\
7 & Methotrexate $^{*}$ & 10 \\
8 & Vinblastine $^{*}$ & 6 \\
9 & Megestrol $^{*}$ & 6 \\
10 & Aminoglutethimide & 2 \\
11 & Letrozole $^{*}$ & 2 \\
12 & MS-275 $^{* *}$ & 2 \\
13 & GW-8510** $^{* *}$ & 0 \\
14 & Phenoxybenzamine $^{* *}$ & 0 \\
15 & Tyrphostin_AG-825 $^{* *}$ & 0 \\
16 & Alsterpaullone & 0 \\
17 & Celastrol $^{* *}$ & 0 \\
\hline$*$
\end{tabular}

${ }^{*}$ Known breast cancer drug. ${ }^{* *}$ Potential drug candidate for repositioning.

phenotype expression profiles (CMap) using semisupervised learning. The proposed pathway-based drug repositioning process showed encouraging results when using four different disease expression profiles to predict candidate drugs for disease-specific repositioning.

Two different methods were employed to evaluate the repositioned drugs. The drugs that passed both evaluation methods successfully were considered the most promising drugs to target breast cancer. As a result, several drugs, including camptothecin, MS-275, alsterpaullone, GW-8510, AG 825, and celastrol were identified as possible drugs to be repositioned to treat breast cancer, and these results are supported by multiple lines of evidence in the public
TABLE 11: PageRank of promising drug candidates on the validation network $(\alpha=0.85)$.

\begin{tabular}{lcc}
\hline Rank & Drug name & Ranking score \\
\hline 1 & Tamoxifen $^{*}$ & 0.990 \\
2 & Doxorubicin* $^{*}$ & 0.692 \\
3 & Paclitaxel $^{*}$ & 0.663 \\
4 & Methotrexate $^{*}$ & 0.373 \\
5 & Fulvestrant $^{*}$ & 0.316 \\
6 & Camptothecin $^{* *}$ & 0.257 \\
7 & Letrozole $^{*}$ & 0.252 \\
8 & Vinblastine $^{*}$ & 0.235 \\
9 & Exemestane* $^{*}$ & 0.176 \\
10 & Aminoglutethimide* $^{*}$ & 0.108 \\
11 & Alsterpaullone $^{* *}$ & 0.102 \\
12 & Megestrol $^{*}$ & 0.101 \\
13 & MS-275 $^{* *}$ & 0.088 \\
14 & Phenoxybenzamine $^{* *}$ & 0.080 \\
15 & GW-8510** $^{* *}$ & 0.026 \\
16 & Celastrol $^{* *}$ & 0.023 \\
17 & Tyrphostin_AG-825** $^{*}$ & 0.010 \\
\hline
\end{tabular}

${ }^{*}$ Known breast cancer drug. ${ }^{* *}$ Potential drug candidate for repositioning.

literature. Specifically, camptothecin was the most promising drug candidate because it showed a high network property on the validation network and was supported by evidence in the literature.

Despite the interesting results, our method for drug repositioning was developed and validated in only using integrated mRNA gene expression profiles. However, the strategy can be easily improved to include other experimental data types, such as RNA-seq, miRNA, DNA-methylation, and single nucleotide polymorphism (SNP) information. Finally, the increasing number of genomic and pharmaceutical databases necessitates the further development of the method to identify new drugs and targets for rare cancer 
subtypes, develop personalized medicine, and design targeted cancer therapies.

\section{Competing Interests}

The authors declare that there is no conflict of interests regarding the publication of this paper.

\section{Acknowledgments}

This study was supported by the BK21 Plus project funded by the Ministry of Education, Korea (21A20131600011).

\section{References}

[1] T. T. Ashburn and K. B. Thor, "Drug repositioning: identifying and developing new uses for existing drugs," Nature Reviews Drug Discovery, vol. 3, no. 8, pp. 673-683, 2004.

[2] T. I. Oprea and J. Mestres, "Drug repurposing: far beyond new targets for old drugs," The AAPS Journal, vol. 14, no. 4, pp. 759$763,2012$.

[3] F. Napolitano, Y. Zhao, V. M. Moreira et al., "Drug repositioning: a machine-learning approach through data integration," Journal of Cheminformatics, vol. 5, no. 1, pp. 1-9, 2013.

[4] J. Li, S. Zheng, B. Chen, A. J. Butte, S. J. Swamidass, and Z. Lu, "A survey of current trends in computational drug repositioning," Briefings in Bioinformatics, vol. 17, no. 1, pp. 2-12, 2016.

[5] S. J. Swamidass, "Mining small-molecule screens to repurpose drugs," Briefings in Bioinformatics, vol. 12, no. 4, pp. 327-335, 2011.

[6] J. Lamb, E. D. Crawford, D. Peck et al., "The connectivity map: using gene-expression signatures to connect small molecules, genes, and disease," Science, vol. 313, no. 5795, pp. 1929-1935, 2006.

[7] J. Lamb, "The connectivity map: a new tool for biomedical research," Nature Reviews Cancer, vol. 7, no. 1, pp. 54-60, 2007.

[8] F. Iorio, R. Tagliaferri, and D. Di Bernardo, "Identifying network of drug mode of action by gene expression profiling," Journal of Computational Biology, vol. 16, no. 2, pp. 241-251, 2009.

[9] A. Subramanian, P. Tamayo, V. K. Mootha et al., "Gene set enrichment analysis: a knowledge-based approach for interpreting genome-wide expression profiles," Proceedings of the National Academy of Sciences of the United States of America, vol. 102, no. 43, pp. 15545-15550, 2005.

[10] Y. Silberberg, A. Gottlieb, M. Kupiec, E. Ruppin, and R. Sharan, "Large-scale elucidation of drug response pathways in humans," Journal of Computational Biology, vol. 19, no. 2, pp. 163-174, 2012.

[11] F. Iorio, R. Bosotti, E. Scacheri et al., "Discovery of drug mode of action and drug repositioning from transcriptional responses," Proceedings of the National Academy of Sciences of the United States of America, vol. 107, no. 33, pp. 14621-14626, 2010.

[12] J. A. Parkkinen and S. Kaski, "Probabilistic drug connectivity mapping," BMC Bioinformatics, vol. 15, article 113, 2014.

[13] J. Yu, P. Putcha, and J. M. Silva, "Recovering drug-induced apoptosis subnetwork from connectivity map data," BioMed Research International, vol. 2015, Article ID 708563, 11 pages, 2015.

[14] A. Pujol, R. Mosca, J. Farrés, and P. Aloy, "Unveiling the role of network and systems biology in drug discovery," Trends in Pharmacological Sciences, vol. 31, no. 3, pp. 115-123, 2010.
[15] H. Chen, H. Zhang, Z. Zhang, Y. Cao, and W. Tang, "Networkbased inference methods for drug repositioning," Computational and Mathematical Methods in Medicine, vol. 2015, Article ID 130620, 7 pages, 2015.

[16] V. Law, C. Knox, Y. Djoumbou et al., "DrugBank 4.0: shedding new light on drug metabolism," Nucleic Acids Research, vol. 42, no. 1, pp. D1091-D1097, 2014.

[17] A. Hamosh, A. F. Scott, J. S. Amberger, C. A. Bocchini, and V. A. McKusick, "Online Mendelian Inheritance in Man (OMIM), a knowledgebase of human genes and genetic disorders," Nucleic Acids Research, vol. 33, pp. D514-D517, 2005.

[18] D. Emig, A. Ivliev, O. Pustovalova et al., "Drug target prediction and repositioning using an integrated network-based approach," PLoS ONE, vol. 8, no. 4, Article ID e60618, 2013.

[19] G. H. Hu and P. Agarwal, "Human disease-drug network based on genomic expression profiles," PLoS ONE, vol. 4, no. 8, Article ID e6536, 2009.

[20] M. A. Yildirim, K.-I. Goh, M. E. Cusick, A.-L. Barabási, and M. Vidal, "Drug-target network," Nature Biotechnology, vol. 25, no. 10, pp. 1119-1126, 2007.

[21] M. J. Keiser, B. L. Roth, B. N. Armbruster, P. Ernsberger, J. J. Irwin, and B. K. Shoichet, "Relating protein pharmacology by ligand chemistry," Nature Biotechnology, vol. 25, no. 2, pp. 197206, 2007.

[22] F. Tan, R. Yang, X. Xu et al., "Drug repositioning by applying 'expression profiles' generated by integrating chemical structure similarity and gene semantic similarity," Molecular BioSystems, vol. 10, no. 5, pp. 1126-1138, 2014.

[23] M. Kuhn, C. von Mering, M. Campillos, L. J. Jensen, and P. Bork, "STITCH: interaction networks of chemicals and proteins," Nucleic Acids Research, vol. 36, no. 1, pp. D684-D688, 2008.

[24] F. Zhu, Z. Shi, C. Qin et al., “Therapeutic target database update 2012: a resource for facilitating target-oriented drug discovery," Nucleic Acids Research, vol. 40, no. 1, pp. D1128-D1136, 2012.

[25] A. Ramasamy, A. Mondry, C. C. Holmes, and D. G. Altman, "Key issues in conducting a meta-analysis of gene expression microarray datasets," PLoS Medicine, vol. 5, no. 9, p. e184, 2008.

[26] M. Iskar, M. Campillos, M. Kuhn, L. J. Jensen, V. van Noort, and P. Bork, "Drug-induced regulation of target expression," PLoS Computational Biology, vol. 6, no. 9, Article ID e1000925, 2010.

[27] F. Napolitano, F. Sirci, D. Carrella, and D. di Bernardo, "Drugset enrichment analysis: a novel tool to investigate drug mode of action," Bioinformatics, vol. 32, no. 2, pp. 235-241, 2016.

[28] I. B. Pau Ni, Z. Zakaria, R. Muhammad et al., "Gene expression patterns distinguish breast carcinomas from normal breast tissues: the Malaysian context," Pathology Research and Practice, vol. 206, no. 4, pp. 223-228, 2010.

[29] K. Graham, A. De Las Morenas, A. Tripathi et al., "Gene expression in histologically normal epithelium from breast cancer patients and from cancer-free prophylactic mastectomy patients shares a similar profile," British Journal of Cancer, vol. 102, no. 8, pp. 1284-1293, 2010.

[30] Y. Wang, J. G. M. Klijn, Y. Zhang et al., “Gene-expression profiles to predict distant metastasis of lymph-node-negative primary breast cancer," The Lancet, vol. 365, no. 9460, pp. 671-679, 2005.

[31] C. Sotiriou, P. Wirapati, S. Loi et al., "Gene expression profiling in breast cancer: understanding the molecular basis of histologic grade to improve prognosis," Journal of the National Cancer Institute, vol. 98, no. 4, pp. 262-272, 2006.

[32] R. Edgar, M. Domrachev, and A. E. Lash, "Gene Expression Omnibus: NCBI gene expression and hybridization array data 
repository," Nucleic Acids Research, vol. 30, no. 1, pp. 207-210, 2002.

[33] R. A. Irizarry, B. Hobbs, F. Collin et al., "Exploration, normalization, and summaries of high density oligonucleotide array probe level data," Biostatistics, vol. 4, no. 2, pp. 249-264, 2003.

[34] K. A. Gray, B. Yates, R. L. Seal, M. W. Wright, and E. A. Bruford, "Genenames.org: the HGNC resources in 2015," Nucleic Acids Research, vol. 43, no. D1, pp. D1079-D1085, 2015.

[35] A. Liberzon, A. Subramanian, R. Pinchback, H. Thorvaldsdóttir, P. Tamayo, and J. P. Mesirov, "Molecular signatures database (MSigDB) 3.0," Bioinformatics, vol. 27, no. 12, pp. 1739-1740, 2011.

[36] M. Kanehisa, M. Araki, S. Goto et al., "KEGG for linking genomes to life and the environment," Nucleic Acids Research, vol. 36, no. 1, pp. D480-D484, 2008.

[37] L. Matthews, G. Gopinath, M. Gillespie et al., "Reactome knowledgebase of human biological pathways and processes," Nucleic Acids Research, vol. 37, no. 1, pp. D619-D622, 2009.

[38] D. Szklarczyk, A. Franceschini, S. Wyder et al., "STRING v10: protein-protein interaction networks, integrated over the tree of life," Nucleic Acids Research, vol. 43, no. 1, pp. D447-D452, 2015.

[39] M. Kuhn, D. Szklarczyk, S. Pletscher-Frankild et al., "STITCH 4: integration of protein-chemical interactions with user data," Nucleic Acids Research, vol. 42, no. D1, pp. D401-D407, 2014.

[40] H. Jandu, K. Aluzaite, L. Fogh et al., "Molecular characterization of irinotecan (SN-38) resistant human breast cancer cell lines," BMC Cancer, vol. 16, no. 1, article 34, 2016.

[41] H.-J. Kim, S.-A. Im, B. Keam et al., "ABCB1 polymorphism as prognostic factor in breast cancer patients treated with docetaxel and doxorubicin neoadjuvant chemotherapy," Cancer Science, vol. 106, no. 1, pp. 86-93, 2015.

[42] E. Devarajan, A. A. Sahin, J. S. Chen et al., "Down-regulation of caspase 3 in breast cancer: a possible mechanism for chemoresistance," Oncogene, vol. 21, no. 57, pp. 8843-8851, 2002.

[43] B. M. Müller, L. Jana, A. Kasajima et al., "Differential expression of histone deacetylases HDAC1, 2 and 3 in human breast cancer-overexpression of HDAC2 and HDAC3 is associated with clinicopathological indicators of disease progression," BMC Cancer, vol. 13, no. 1, article 215, pp. 1-8, 2013.

[44] E. A. Musgrove, C. E. Caldon, J. Barraclough, A. Stone, and R. L. Sutherland, "Cyclin D as a therapeutic target in cancer," Nature Reviews Cancer, vol. 11, no. 8, pp. 558-572, 2011.

[45] S. Nidhyanandan, T. S. Boreddy, K. B. Chandrasekhar, N. D. Reddy, N. M. Kulkarni, and S. Narayanan, "Phosphodiesterase inhibitor, pentoxifylline enhances anticancer activity of histone deacetylase inhibitor, MS-275 in human breast cancer in vitro and in vivo," European Journal of Pharmacology, vol. 764, pp. 508-519, 2015.

[46] R. K. Srivastava, R. Kurzrock, and S. Shankar, "MS-275 sensitizes TRAIL-resistant breast cancer cells, inhibits angiogenesis and metastasis, and reverses epithelial-mesenchymal transition in vivo," Molecular Cancer Therapeutics, vol. 9, no. 12, pp. 32543266, 2010.

[47] T. R. Singh, S. Shankar, and R. K. Srivastava, "HDAC inhibitors enhance the apoptosis-inducing potential of TRAIL in breast carcinoma," Oncogene, vol. 24, no. 29, pp. 4609-4623, 2005.

[48] Y. Y. Hsieh, C. J. Chou, H. L. Lo, and P. M. Yang, "Repositioning of a cyclin-dependent kinase inhibitor GW8510 as a ribonucleotide reductase M2 inhibitor to treat human colorectal cancer," Cell Death Discovery, vol. 2, Article ID 16027, 2016.
[49] F.-H. Chung, Y.-R. Chiang, A.-L. Tseng et al., "Functional Module Connectivity Map (FMCM): a framework for searching repurposed drug compounds for systems treatment of cancer and an application to colorectal adenocarcinoma," PLOS ONE, vol. 9, no. 1, Article ID e86299, 2014.

[50] R. A. Shamanna, H. Lu, D. L. Croteau et al., "Camptothecin targets WRN protein: mechanism and relevance in clinical breast cancer," Oncotarget, vol. 7, no. 12, pp. 13269-13284, 2016.

[51] S. J. Conley, T. L. Baker, J. P. Burnett et al., "CRLX101, an investigational camptothecin-containing nanoparticle-drug conjugate, targets cancer stem cells and impedes resistance to antiangiogenic therapy in mouse models of breast cancer," Breast Cancer Research and Treatment, vol. 150, no. 3, pp. 559567, 2015.

[52] J. T. Sims, S. Ganguly, L. S. Fiore, C. J. Holler, E.-S. Park, and R. Plattner, "STI571 sensitizes breast cancer cells to 5fluorouracil, cisplatin and camptothecin in a cell type-specific manner," Biochemical Pharmacology, vol. 78, no. 3, pp. 249-260, 2009.

[53] A. Fujimori, M. Gupta, Y. Hoki, and Y. Pommier, "Acquired camptothecin resistance of human breast cancer MCF-7/C4 cells with normal topoisomerase I and elevated DNA repair," Molecular Pharmacology, vol. 50, no. 6, pp. 1472-1478, 1996.

[54] L. G. Sheffield, "C-Src activation by ErbB2 leads to attachmentindependent growth of human breast epithelial cells," Biochemical and Biophysical Research Communications, vol. 250, no. 1, pp. 27-31, 1998.

[55] D. Kedrin, J. Wyckoff, P. J. Boimel et al., "ERBB1 and ERBB2 have distinct functions in tumor cell invasion and intravasation," Clinical Cancer Research, vol. 15, no. 11, pp. 3733-3739, 2009.

[56] Sigma-Aldrich, Tyrphostin AG 825: Highlights of Prescribing Information, Sigma-Aldrich, 2016.

[57] C. C. Faria, S. Agnihotri, S. C. Mack et al., "Identification of alsterpaullone as a novel small molecule inhibitor to target group 3 medulloblastoma," Oncotarget, vol. 6, no. 25, pp. 2171821729, 2015.

[58] J.-I. Chao, W.-C. Su, and H.-F. Liu, "Baicalein induces cancer cell death and proliferation retardation by the inhibition of CDC2 kinase and survivin associated with opposite role of p38 mitogen-activated protein kinase and AKT," Molecular Cancer Therapeutics, vol. 6, no. 11, pp. 3039-3048, 2007.

[59] S. Shrivastava, M. K. Jeengar, V. S. Reddy, G. B. Reddy, and V. G. M. Naidu, "Anticancer effect of celastrol on human triple negative breast cancer: possible involvement of oxidative stress, mitochondrial dysfunction, apoptosis and PI3K/Akt pathways," Experimental and Molecular Pathology, vol. 98, no. 3, pp. 313$327,2015$.

[60] C. Mi, H. Shi, J. Ma, L. Z. Han, J. J. Lee, and X. Jin, "Celastrol induces the apoptosis of breast cancer cells and inhibits their invasion via downregulation of MMP-9," Oncology Reports, vol. 32, no. 6, pp. 2527-2532, 2014. 

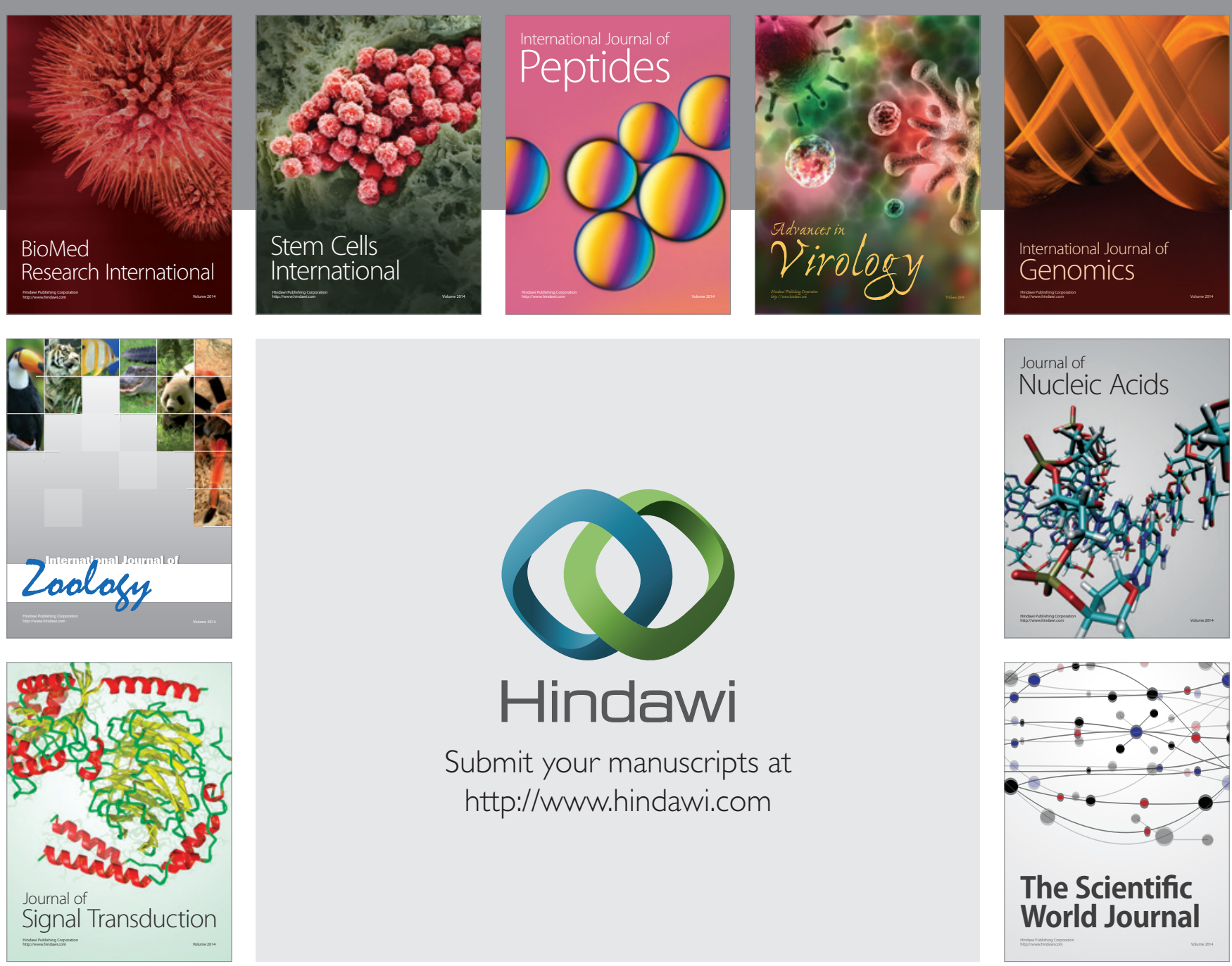

Submit your manuscripts at

http://www.hindawi.com
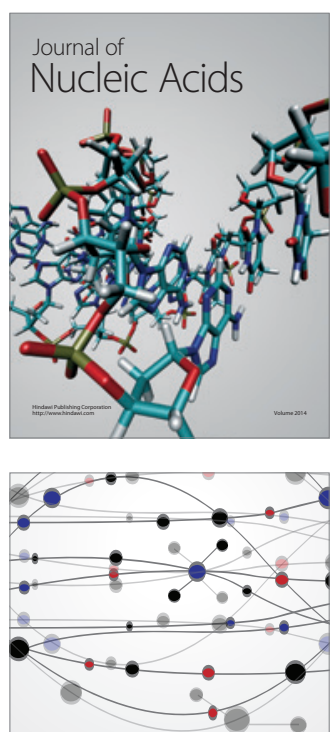

The Scientific World Journal
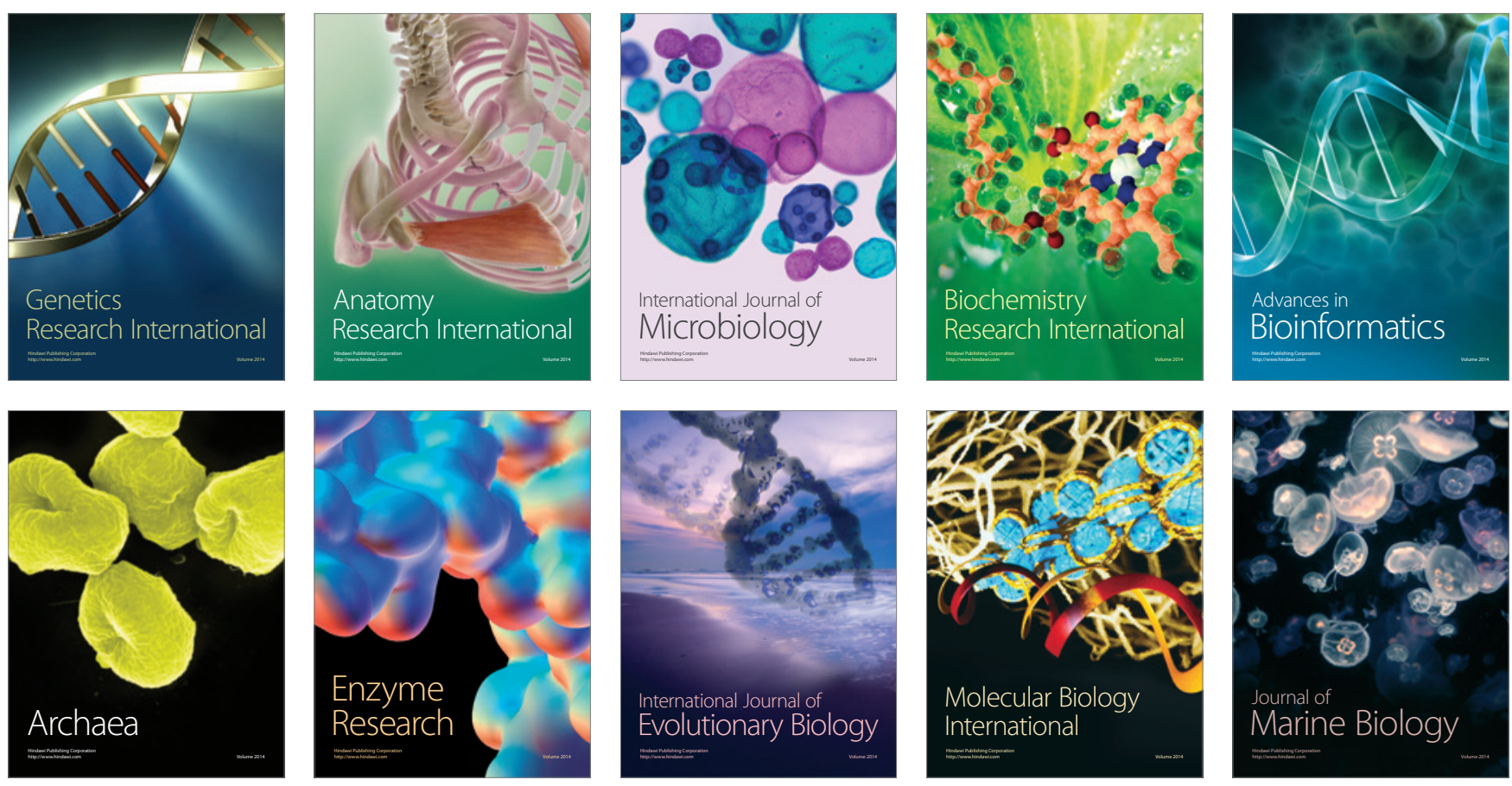